\title{
Combined Treatment with the Mood Stabilizers Lithium and Valproate Produces Multiple Beneficial Effects in Transgenic Mouse Models of Huntington's Disease
}

\author{
Chi-Tso Chiu', Guangping Liu', Peter Leeds' and De-Maw Chuang*,' \\ 'Section on Molecular Neurobiology, National Institute of Mental Health, National Institutes of Health, Bethesda, MD, USA
}

\begin{abstract}
Emerging evidence suggests that the mood stabilizers lithium and valproate (VPA) have broad neuroprotective and neurotrophic properties, and that these occur via inhibition of glycogen synthase kinase 3 (GSK-3) and histone deacetylases (HDACs), respectively. Huntington's disease (HD) is an inherited neurodegenerative disorder characterized by impaired movement, cognitive and psychiatric disturbances, and premature death. We treated $\mathrm{NI} 7 \mathrm{I}-82 \mathrm{Q}$ and YACI28 mice, two mouse models of HD varying in genetic backgrounds and pathological progressions, with a diet containing therapeutic doses of lithium, VPA, or both. Untreated, these transgenic mice displayed a decrease in levels of GSK-3 $\beta$ serine 9 phosphorylation and histone $\mathrm{H} 3$ acetylation in the striatum and cerebral cortex around the onset of behavioral deficits, indicating a hyperactivity of GSK-3 $\beta$ and HDACs. Using multiple well-validated behavioral tests, we found that co-treatment with lithium and VPA more effectively alleviated spontaneous locomotor deficits and depressive-like behaviors in both models of HD mice. Furthermore, compared with monotherapy with either drug alone, co-treatment more successfully improved motor skill learning and coordination in NI7I-82Q mice, and suppressed anxiety-like behaviors in YACI 28 mice. This combined treatment consistently inhibited GSK-3 $\beta$ and HDACs, and caused a sustained elevation in striatal as well as cortical brain-derived neurotrophic factor and heat shock protein 70. Importantly, co-treatment markedly prolonged median survival of NI7I-82Q mice from 31.6 to 4I.6 weeks. Given that there is presently no proven treatment for HD, our results suggest that combined treatment with lithium and VPA, two mood stabilizers with a long history of safe use in humans, may have important therapeutic potential for HD patients.

Neuropsychopharmacology (20I I) 36, 2406-242I; doi: I0.1038/npp.20I I.I28; published online 27 July 201 I
\end{abstract}

Keywords: Huntington's disease; lithium; valproate; GSK-3; HDACs; transgenic mouse model

\section{INTRODUCTION}

Huntington's disease (HD) is an inherited, autosomaldominant neurodegenerative disease. It belongs to the family of polyglutamine (polyQ) disorders and is caused by an abnormal expansion of a trinucleotide CAG repeat in the gene that encodes a polyQ stretch in the disease-causing protein huntingtin (MacDonald et al, 1993). The presence of this mutant protein results in a selective loss of neurons in the brain, particularly medium-sized spiny neurons in the striatum and, to a lesser extent, neurons in the cortex (Friedlander, 2003; Hickey and Chesselet, 2003). Transcriptional dysregulation also has a central role in the pathogenesis/pathophysiology of this disease (Hodges et al, 2006;

*Correspondence: Dr D-M Chuang, Section on Molecular Neurobiology, National Institute of Mental Health, National Institutes of Health, Building 10, Room 3D38, 10 Center Drive, MSC 1363, Bethesda, MD 20892-| 363, USA, Tel: + | 30 | 496 49|5, Fax: + I 30 | 4809290 , E-mail: chuang@mail.nih.gov

Received 8 April 20 II; revised 2 June 201 I; accepted I6 June 201 I
Sugars and Rubinsztein, 2003). HD patients suffer from various cognitive, psychiatric, and physical symptoms, such as memory loss, changes in personality, and emotional deterioration, in addition to jerky and uncontrollable movements (Martin and Gusella, 1986). Most HD patients are adult-onset, and usually develop symptoms between the ages of 35 and 44 years. HD is lethal; it leads to death about 15 years after the initial symptom occurs. Currently, no proven treatment exists to arrest or reverse the course of this disease.

Lithium, a monovalent cation, has been the standard pharmacological treatment for bipolar disorder for more than half a century. It remains the first-line treatment against acute mania, and prophylactically for recurrent manic and depressive episodes. Valproate (VPA), an anticonvulsant drug, is also effective in treating bipolar disorder. The precise mechanisms for how these drugs work are still poorly understood. Nevertheless, significant attention during the past decade has focused on the power of these two mood stabilizers to protect against diverse insults in vitro and in vivo, including apoptosis, oxidative stress, 
transcriptional dysregulation, and excitotoxicity (for review, see Chuang, 2005). The neurotoxic mechanisms of these insults have been implicated in the pathogenesis of several neurodegenerative diseases, including HD (for review, see Friedlander, 2003; Stack and Ferrante, 2007). Emerging evidence indicates lithium and VPA have the ability to affect transcriptional activity and gene expression, and to promote cell proliferation and likely neurogenesis in the CNS. These actions of lithium and VPA are suggested to be mediated via the inhibition of glycogen synthase kinase 3 (GSK-3) and histone deacetylases (HDACs), respectively (Göttlicher et al, 2001; Klein and Melton, 1996; Phiel et al, 2001; Ryves and Harwood, 2001). Clinically, lithium in combination with other mood stabilizers such as VPA has been used to enhance the therapeutic benefits or to treat bipolar patients insensitive to single drug therapy. These findings raise the possibility that lithium and VPA co-treatment may produce stronger or synergistic effects against neuronal cell death in neurodegenerative conditions. To date, however, no studies investigating combined lithium and VPA treatment in HD have been conducted.

HD pathogenesis is frequently modeled with the expression of mutant huntingtin that causes aggregate formation and toxicity in cell models and in vivo (Rubinsztein, 2002). Although no single model can recapitulate exact human pathology, different aspects of a disease may be revealed by multiple animal models. Therefore, we investigated the therapeutic potential of lithium and VPA in two widely used transgenic mouse models of HD, N171-82Q and YAC128, in this study. N171-82Q mice exhibit poor motor coordination and die prematurely, whereas YAC128 mice show a slower progression in cognitive and motor impairments and have a normal lifespan (Schilling et al, 1999; Slow et al, 2003). Although not additive or synergistic in every aspect of this disease, we demonstrated that co-treatment with lithium and VPA produced overall reliable behavioral benefits in both HD models and, importantly, prolonged survival time in N171-82Q mice. In addition, GSK-3 $\beta$ and HDAC hyperactivity was consistently suppressed by this combined treatment regimen, which was also associated with upregulation of two important proteins for neuronal growth and protection, the brain-derived neurotrophic factor (BDNF) and heat shock protein 70 (HSP70), respectively, in the brains of HD mice. Lithium and VPA are already FDAapproved medications; our data provide the rationale and clinical relevance for the combined treatment of HD with these two mood stabilizers.

\section{SUBJECTS AND METHODS}

\section{Animals}

Heterozygous male transgenic HD mice from the N171-82Q and YAC128 strains were purchased from Jackson Laboratory (Bar Harbor, ME) and maintained as colonies in the animal facility at the National Institutes of Health (NIH). Male transgenic HD mice were bred with wild-type females from their background strains (N171-82Q: B6C3F1/J; YAC128: FVB/N) and offspring were genotyped using polymerase chain reaction (PCR) at 1 month of age. Animals were housed in groups of four with littermates of mixed genotype on a normal 12-h light-dark cycle, and at constant temperature $\left(22 \pm 2{ }^{\circ} \mathrm{C}\right)$. Food and water were available ad libitum except during behavioral testing. Sex- and agematched (within 3 days) animals were used in this study. All procedures for animal handling and animal experiments were approved by the Animal Care and Use Committee of the NIH, and performed in compliance with the Guide for the Care and Use of Laboratory Animals (ISBN: 978-0309053778).

\section{Drug Treatment}

Baseline behaviors were first measured in all mice (see below). Mice were subsequently fed either control chow, or an equivalent diet containing lithium carbonate $(3 \mathrm{~g} / \mathrm{kg}$; Sigma-Aldrich, St Louis, MO), sodium VPA (25 g/kg; SigmaAldrich), or both. Doses were chosen based on a pilot dose-response study indicating that blood concentrations of both drugs were within the therapeutic levels for human patients with bipolar disorder (Table 1). Customized rodent diets were purchased from Bio-Serv (Frenchtown, NJ). No significant impact on the health of the animals was observed after chronic drug treatment.

\section{Behavioral Tests}

Mice underwent a battery of affect-related tests: the openfield test, the elevated zero-maze test, the accelerating rotarod test, the forced swim test (FST), and the tail suspension test (TST). All tests were conducted during the animals' light cycle (between 1000 and 1600 hours). Animals of both genders were employed in behavioral testing because gender had no significant effect in these tests. Mice were transported to a separate testing room in their home cages and allowed to acclimate for 60-min undisturbed with food and water before all tests.

Open-field test. The open-field test is widely used to assess locomotor activity and anxiety-like behaviors (Crawley, 1985). The spontaneous locomotor activity of the animals was measured using an automated photo-beam open-field system (Med-Associates, St Albans, VT). Mice were placed individually in the center of a clear open-field chamber $(27.9 \mathrm{~cm} \times 27.9 \mathrm{~cm} \times 20 \mathrm{~cm})$, and their horizontal locomotor activities were measured immediately for $30 \mathrm{~min}$ with three 16-beam I/R arrays. Locomotor activity was assessed as the distance traveled in 5-min intervals. Bright illumination from centrally placed regular ceiling lights was used. As the open-field test has also been used as a paradigm for

Table I Serum Concentrations of Drugs After Long-Term Dietary Treatment in HD Mice

\begin{tabular}{lcc}
\hline & Lithium (mM) & VPA $(\boldsymbol{\mu g} / \mathbf{m l})$ \\
\hline NI7I-82Q & $0.95 \pm 0.14$ & $75.68 \pm 2.37$ \\
YACI28 & $1.17 \pm 0.04$ & $78.44 \pm 16.05$ \\
\hline
\end{tabular}

Samples were obtained from NI7I-82Q and YACI 28 mice after long-term dietary treatment with lithium carbonate $(3 \mathrm{~g} / \mathrm{kg})$ or sodium VPA $(25 \mathrm{~g} / \mathrm{kg})$, from 7 to 22 weeks and from 3 to 12 months of age, respectively. Data are mean $\pm \operatorname{SEM}(n=5)$. 
measuring anxiety-like behaviors, time spent in the center of the open field $(14 \mathrm{~cm} \times 14 \mathrm{~cm})$ and distance traveled in the center region were further recorded. An increase in the amount of time spent in the center region was considered to indicate reduced anxiety.

Elevated zero-maze test. Anxiety-like behaviors in the mice were further investigated using the elevated zero-maze (San Diego Instruments, San Diego, CA) as described previously (Shepherd et al, 1994). Briefly, the apparatus comprises an elevated circular platform $(63.5 \mathrm{~cm}$. in diameter) with two open and two closed quadrants. Each individual mouse was placed in the center of one of the closed quadrants and allowed to explore uninterrupted for $5 \mathrm{~min}$. Anxiety-like behaviors were measured as the time an animal spent in the open or closed quadrants, with increased time spent in the open quadrants considered to be a measure of reduced anxiety (Shepherd et al, 1994). Mice that fell off the maze were excluded. Tests were video recorded and analyzed off-line by the ANY-maze video-tracking system (Stoelting, Wood Dale, IL).

Accelerating rotarod test. Motor skill learning and coordination in the mice were measured using an accelerating rotarod apparatus (San Diego Instruments; Buitrago et al, 2004; Jones and Roberts, 1968). N171-82Q mice received a training session of four trials per day with a 10-min rest between trials for 4 consecutive days at each time point measured. During a trial, the rotarod was accelerated from 0 to 30 r.p.m. over $4 \mathrm{~min}$ and then remained at 30 r.p.m. for an additional minute. Each trial lasted until the mouse fell from the rod or for a maximum of $5 \mathrm{~min}$. The average rotarod performance was calculated using the best rotarod performance of each day of the 4-day trials.

Forced swim test. The FST (also known as the Porsolt test) was performed to evaluate depressive-like behaviors in mice. This test is a standard measure of the antidepressant effects of various agents. Briefly, each mouse was placed for $6 \mathrm{~min}$ in a $25-\mathrm{cm}$ tall, $16-\mathrm{cm}$ diameter transparent cylindrical tank filled with water to $20 \mathrm{~cm}$, a depth at which the mouse could reach neither the top nor the bottom of the tank. Water temperature was maintained at room temperature $\left(\sim 22^{\circ} \mathrm{C}\right)$. All test sessions were videotaped and results were analyzed off-line by ANY-maze video-tracking system (Stoelting). Immobility, defined as a lack of activity as well as movements made by the mouse to keep its nose above water, was scored during the last $4 \mathrm{~min}$ of the session; decreased swimming time (or increased floating time) was considered a measure of depressive-like behaviors (Porsolt et al, 1977).

Tail suspension test. The TST was conducted as previously described (Steru et al, 1985) and used as an additional indictor to confirm the depressive-like behaviors displayed in the FST. Briefly, mice were suspended individually by the tail using non-irritating adhesive tape placed at about half the total tail length to a hook connected to a horizontal bar. Each test session lasted for $6 \mathrm{~min}$ and total immobility time was analyzed off-line by ANY-maze system (Stoelting).

\section{Brain Sample Preparation and Western Blot Analysis}

Mice were killed by decapitation and the striatum and cerebral cortex were dissected quickly at the time indicated. Brain tissue for western blotting was frozen immediately on dry ice and stored at $-80{ }^{\circ} \mathrm{C}$ until further use. Brain tissue for real-time PCR was stored in RNAlater RNA Stabilization reagent (Qiagen, Valencia, CA) and kept at $-20^{\circ} \mathrm{C}$. For western blot analyses, brain tissues were homogenized in $3 \%(\mathrm{w} / \mathrm{v})$ ice-cold T-PER tissue protein extraction reagent (Thermo Scientific, Rockford, IL) containing protease and phosphatase inhibitor cocktails (Thermo Scientific). The homogenates were centrifuged at $20000 \mathrm{~g}$ for $10 \mathrm{~min}$ at $4{ }^{\circ} \mathrm{C}$, and the supernatants were used for immunoblotting. Protein content was measured using the BCA protein assay kit (Thermo Scientific) according to the manufacturer's instructions. Samples with equal total protein were separated on a $4-12 \%$ Nupage Bis-Tris gel (Invitrogen, Carlsbad, CA) and transferred onto a nitrocellulose membrane (Invitrogen). Blots were blocked and immunostained overnight at $4{ }^{\circ} \mathrm{C}$ with primary antibody against GSK-3 $\beta$ $(1: 1000$; BD, Franklin Lakes, NJ), phosphorylated GSK-3 $\beta$ at serine 9 (Ser9) $(1: 1000$; Cell Signaling, Beverly, MA), acetylated histone-H3 on both Lys9 and Lys14 (1:2000; Upstate Biotechnology, Lake Placid, NY), BDNF (1:1000; Santa Cruz, Santa Cruz, CA), HSP70 (1:500; Enzo Life Sciences International, Plymouth Meeting, PA), or the house-keeping gene $\beta$-actin $(1: 30000$; Abcam, Cambridge, MA) as a loading control, in blocking buffer (LI-COR, Lincoln, Nebraska) with $0.1 \%$ Tween 20 . Membranes were incubated with a $1: 10000$ dilution of secondary goat antimouse or anti-rabbit antibodies conjugated with IRdye 680 or $800 \mathrm{CW}$ (LI-COR) for $1 \mathrm{~h}$ at room temperature. Finally, blotted proteins were detected and quantified using the Odyssey infrared imaging system (LI-COR). The levels of target protein expression were normalized to that of $\beta$-actin.

\section{RNA Purification and Real-Time PCR}

Total RNA was extracted from brain tissues using the RNeasy Lipid Tissue Mini kit (Qiagen), and reverse transcription was performed from $2 \mu \mathrm{g}$ of total RNA for each sample using the High-Capacity cDNA Reverse Transcription Kits (Applied Biosystems, Foster City, CA) according to the manufacturer's instructions. Quantitative real-time PCR (qRT-PCR) reactions were performed on the 7500 Fast Real Time PCR System (Applied Biosystems) using TaqMan Gene Expression Assays amplification reagent and probes (Applied Biosystems). The expression of $\beta$-actin in each sample was used as the internal control to quantify mRNA expression.

\section{Statistical Analyses}

All statistical analyses were performed using GraphPad Prism (GraphPad, San Diego, CA). Data from male and female mice were combined because no significant gender effect on behavioral tests was observed. Data are expressed as mean \pm standard error of the mean (SEM) and analyzed using a one-way analysis of variance (ANOVA) for a single outcome. Comparisons between genotypes or treatments at individual time points were assessed with a post hoc 
Student's $t$-test when necessary. When phenotypes of wildtype and transgenic HD mice were assessed across ages, two-way ANOVAs (genotype $\times$ age) followed by Bonferroni post tests were used. The significant effects of drug treatment on survival were assessed by Kaplan-Meier analysis.

\section{RESULTS}

\section{Co-Treatment with Lithium and VPA Decreases Body Weight but Prolongs Lifespan in HD Mice}

Serum concentrations of lithium and VPA in N171-82Q and YAC128 HD mice after long-term dietary treatment were within therapeutic levels for human patients with bipolar disorder (Table 1), and were not affected by co-administration (data not shown). No significant difference was found in serum concentrations of the drugs between transgenic mice and their wild-type littermates.

In humans, the progression of $\mathrm{HD}$ is irreversible and leads to death within 15 to 20 years after patients develop clinical features (Gusella and MacDonald, 1995; Vonsattel and DiFiglia, 1998). However, like other HD mice expressing full-length huntingtin (Menalled et al, 2009), the YAC128 mouse model of HD exhibits a relatively normal survival time compared with corresponding wild-type mice. In contrast, and similar to human patients, the N171-82Q mouse model of HD has a shortened lifespan (Schilling et al, 1999). Therefore, we investigated the effect of drug treatment on survival only in N171-82Q mice in this study.

In the control group, the median survival of N171-82Q mice was 31.64 weeks $(n=12)$. Mice of both sexes were included, because the median survival time for male mice (33.36 weeks; $n=6$ ) did not significantly differ from that of female mice (29.86 weeks; $n=6$ ). Long-term monotherapy with lithium beginning at 7 weeks of age did not extend the median survival time in N171-82Q mice (28.14 weeks, $n=8$; Figure 1), while VPA alone markedly increased lifespan to 37.36 weeks $(n=8)$. Co-treatment with lithium and VPA produced a median survival time of 41.57 weeks $(n=14)$. However, when drug treatment began later (at 11, 15, or 19 weeks of age), co-treatment with lithium and VPA did

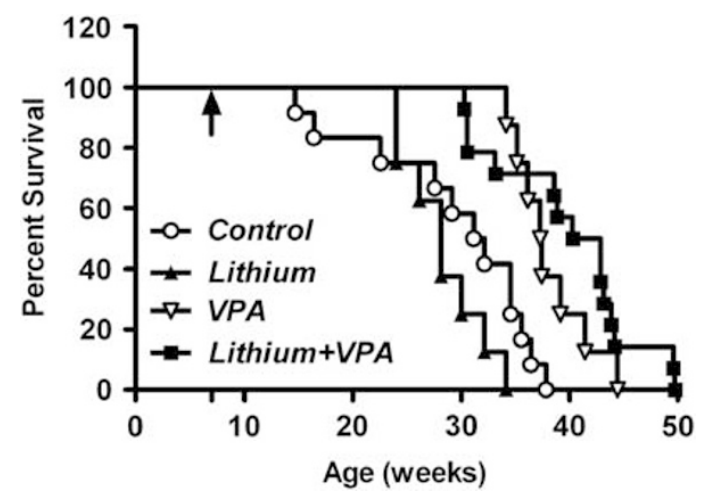

Figure I Early drug treatment prolongs the lifespan of N I7I-82Q mice. Kaplan-Meier analysis revealed that the survival of NI7I-82Q mice was significantly extended by treatment with VPA $(P<0.05)$, but not lithium, starting at 7 weeks of age. Co-treatment with lithium and VPA had a trend to increase the prolonged survival induced by VPA; however, this increase did not reach statistical significance. Arrow indicates the initiation of dietary drug treatment. not significantly prolong lifespan in N171-82Q mice, with median survival times of $34.93,29.07$, and 27.50 weeks, respectively $(n=8)$. Therefore, drug treatments commencing at 7 weeks of age were used in subsequent studies of N171-82Q mice.

Body weight loss is common in HD patients despite adequate nutrition (Morales et al, 1989) and carbohydrateenriched diets (Trejo et al, 2004). Consistent with previous observations in these two mouse models of HD (Schilling et al, 1999; Van Raamsdonk et al, 2007), the body weight of N171-82Q mice did not differ significantly from their wild-type littermates at 6 weeks, but failed to increase after 10 weeks of age (Supplementary Figure S1a). The body weight of YAC128 mice was also similar to their wild-type littermates at 3 months of age, but then increased steadily with age and was significantly greater than that of the wildtype mice throughout the time frame measured (Supplementary Figure S1c). Two-way ANOVA (genotype $\times$ age) revealed significant effects in N171-82Q (genotype: $\mathrm{F}(1,70)=$ 16.54, $P=0.0001$; age: $\mathrm{F}(4,70)=29.48, P<0.0001)$ and in YAC128 mice (genotype: $\mathrm{F}(1,106)=29.68, P<0.0001$; age: $\mathrm{F}(3,106)=9.83, P<0.0001)$.

Instead of improving weight loss in N171-82Q mice, long-term drug treatment with lithium, VPA, or lithium plus VPA beginning at 7 weeks of age further decreased body weight (Supplementary Figure S1b). In YAC128 mice, the heavier body weight was reversed by drug treatment with VPA or co-treatment with lithium beginning at 3 months of age (Supplementary Figure S1d). Despite only moderate serum levels compared with high levels of lithium, VPA had a more drastic effect on weight loss, and coadministration of lithium did not further reduce body weight in YAC128 mice. These drug treatments produced similar effects in the wild-type littermates of N171-82Q mice, but did not significantly affect those of YAC128 mice (Supplementary Figures S1e and f). No apparent clinical symptoms or significant health impact were observed during long-term treatment with either drug.

\section{Lithium-VPA Co-Treatment Effectively Alleviates Spontaneous Locomotor Deficits in HD Mice}

The motor symptoms of HD involve impaired coordination of voluntary as well as involuntary movements. To identify the effects of drug treatment on behavioral changes, N171-82Q and YAC128 mice were examined in motor tests longitudinally, ranging from the ages of 6 to 22 weeks and 3 to 12 months, respectively.

Spontaneous locomotor activity in mice was assessed by the horizontal distance traveled during the 30-min openfield test. In N171-82Q mice, a two-way ANOVA (genotype $\times$ age) revealed significant effects of genotype $(\mathrm{F}(1,98)=46.16$, $P<0.0001)$ and age $(\mathrm{F}(4,98)=3.35, P=0.0129)$ on locomotor activity. N171-82Q mice did not differ significantly from their wild-type littermates at 6 weeks, but as early as 10 weeks were showing significantly decreased locomotor activity compared with their age-matched wildtype littermates (Figure 2a; Bonferroni post test). The total distance traveled did not decrease further after 14 weeks of age in N171-82Q mice. Similarly, locomotor activity in YAC128 mice did not differ significantly from their wildtype littermates at 3 months of age. However, a two-way 

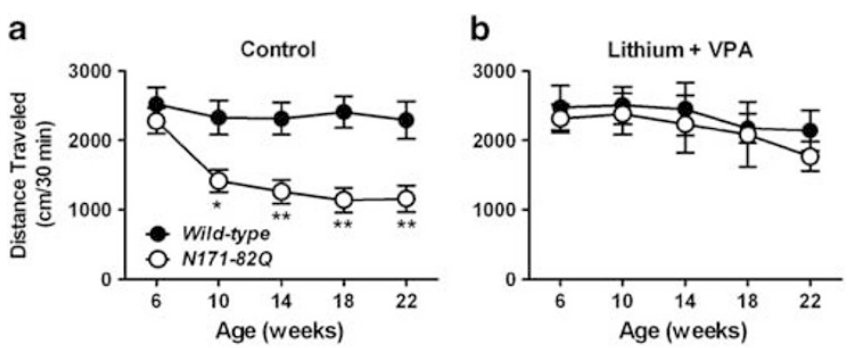

C
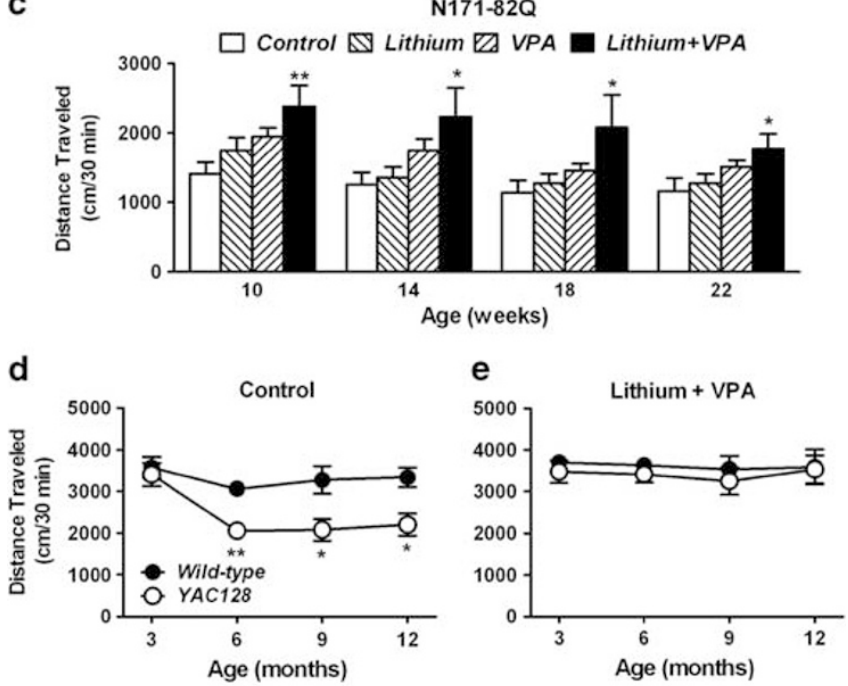

f

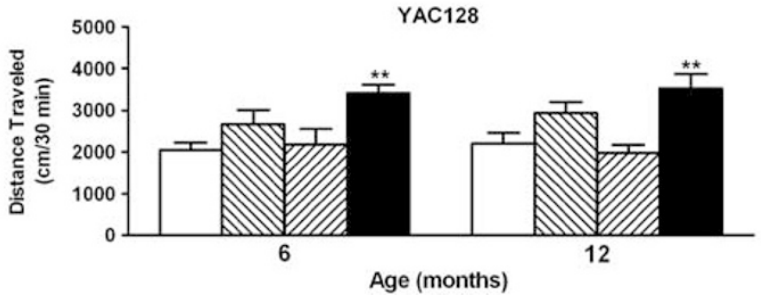

Figure 2 Co-treatment with lithium and VPA effectively alleviates spontaneous locomotor deficits in HD mice. The progressive decreases in spontaneous locomotor activity in $\mathrm{NI} 7 \mathrm{I}-82 \mathrm{Q}$ mice, measured at 10 to 22 weeks of age (a), were prevented by co-treatment with lithium and VPA starting at 7 weeks of age (b). However, no significant effects were produced by long-term treatment with lithium or VPA alone (c). The reduced spontaneous locomotor activity of YACI 28 mice, measured at 6 to 12 months of age (d), was also suppressed by this co-treatment starting at 3 months of age (e). Long-term treatment with lithium or VPA alone produced no significant improvements ( $f$ ). $* P<0.05$, $* * P<0.0$ I, compared with corresponding wild-type or control groups. Data are mean $\pm \operatorname{SEM}(n=5-16)$.

ANOVA (genotype $\times$ age) also revealed significant genotype $(\mathrm{F}(1,98)=24.40, P<0.0001)$ and age $(\mathrm{F}(3,98)=5.64$, $P=0.0013)$ effects on locomotor activity. YAC128 mice exhibited significantly impaired locomotor activity between the ages of 6 to 12 months (Figure 2d; Bonferroni post test).

Long-term treatment of HD mice with either lithium or VPA monotherapy showed a trend to rescue this decreased locomotor activity, but the effects were not consistent at every time point measured, and did not reach statistical significance (Figures $2 \mathrm{c}$ and $\mathrm{f}$ ). In contrast, the effect of drug treatment on locomotor activity was robustly enhanced when these two drugs were administered together. Compared with the transgenic mice not receiving treatment (open bars in Figures $2 \mathrm{c}$ and $\mathrm{f}$ ), the effects of co-treatment with lithium and VPA were significant as early as 10 weeks of age in N171-82Q mice (Figure 2c) and 6 months of age in YAC128 mice (Figure 2f). Combined treatment with lithium and VPA did not affect locomotor activity in wild-type mice (closed symbol; Figures 2a $v s 2 \mathrm{~b} ; 2 \mathrm{~d} v s 2 \mathrm{e}$ ), and no significant difference in locomotor activity was noted between wild-type and transgenic HD mice co-treated with lithium and VPA (Figures $2 \mathrm{~b}$ and $\mathrm{e}$ ).

\section{Co-Treatment with Lithium and VPA Improves Motor Skill Learning and Coordination in N171-82Q Mice}

Motor skill learning and coordination in mice were measured using the accelerating rotarod test, in which motor coordination was quantified by measuring the average rotarod performance calculated from the best performance of each day over 4 days of testing sessions. At 6 weeks, the performance of N171-82Q mice was normal compared with their age-matched wild-type littermates. However, their rotarod performance became impaired with increasing age, while the average rotarod performance of their wild-type mice remained at the same level between 6 and 22 weeks; two-way ANOVA (genotype $\times$ age) revealed a significant effect of genotype on rotarod performance $(\mathrm{F}(1,81)=21.64$, $P<0.0001)$. Compared with their age-matched wild-type littermates, the average rotarod performance of N171-82Q mice significantly decreased at 18 and 22 weeks (Figure 3a; Bonferroni post test). This deficit in N171-82Q mice was progressive over time, with their performance at 22 weeks significantly lower than at 6 weeks $(P<0.05$, one-way repeated-measures ANOVA followed by Dunnett's post tests).

Lithium or VPA monotherapy also showed a trend to improve rotarod performance in N171-82Q mice, but only the effect of lithium reached statistical significance at 18 weeks of age (Figure 3c). Co-treatment with lithium and VPA robustly improved rotarod performance in N171-82Q mice; this effect was significant when measured as early as 14 weeks of age and lasted throughout the course of the experiment (until 22 weeks; Figure 3c). The performance of N171-82Q mice co-treated with lithium and VPA was comparable to the performance of their age-matched wildtype littermates receiving the same treatment (Figure $3 \mathrm{~b}$ ). To examine whether an increase in rotarod performance resulted from decreased body weight, the average latency to fall from the rotarod was plotted against body weight in 14-, 18-, and 22-week-old mice. The regression analysis revealed no correlation between rotarod performance and body weight $\left(r^{2}=0.006, P=0.311\right.$; Figure $\left.3 \mathrm{~d}\right)$.

The acquisition of motor skill needed to achieve improved performance on the rotating rod requires repetitive training sessions and inter-session rest periods. Improved rotarod performance across sessions was therefore used as an indicator of motor skill learning. To further quantify motor learning, the slope was calculated from the best rotarod performance of each day across the 4-day test sessions. At 6 weeks, the performance of N171-82Q mice improved across testing sessions, as did that of their wildtype littermates (Figure 3e). However, the magnitude of improvement in untreated N171-82Q mice was decreased and more rapidly reached a lower plateau with increasing age (Figure 3f; open bars in figure). As in the open-field test, 

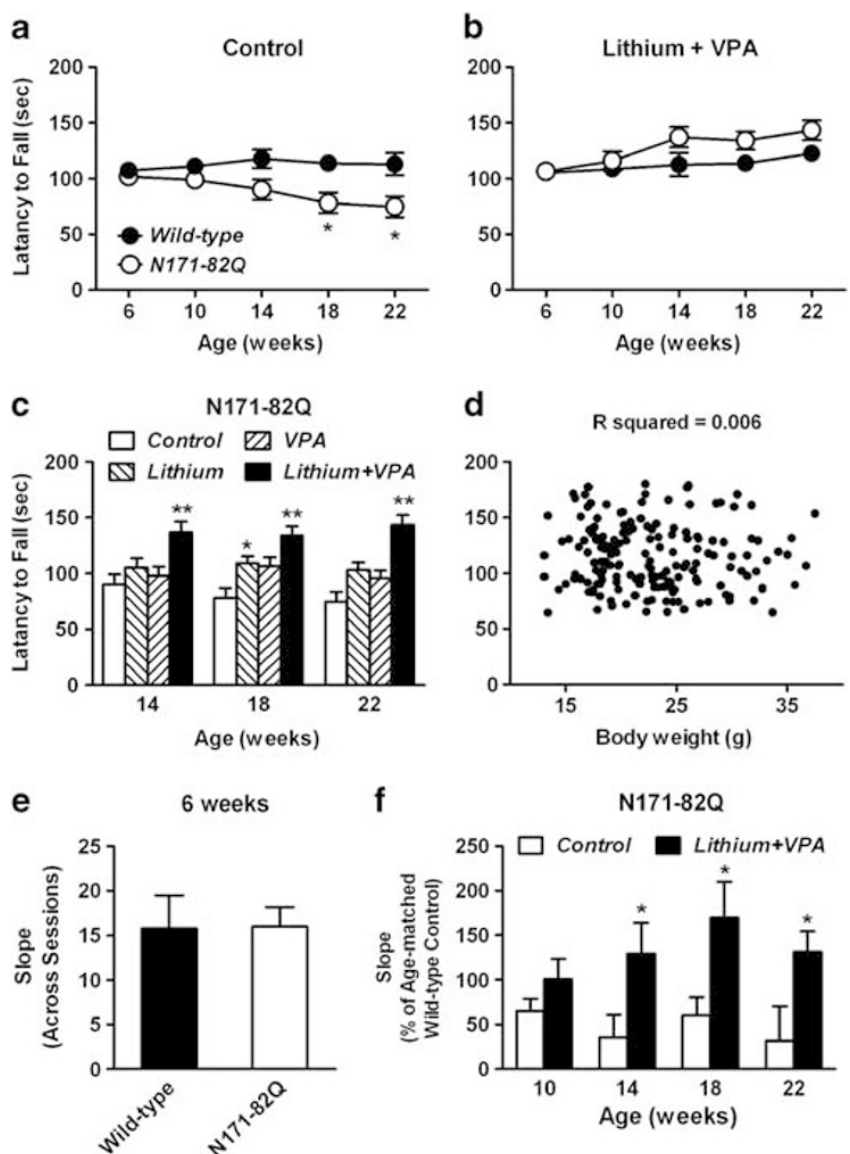

f

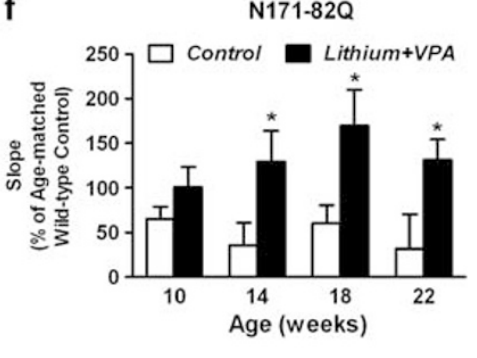

Figure 3 Co-treatment with lithium and VPA improves motor skill learning and coordination in NI7I-82Q mice. The progressive deficits in the rotarod performance of $\mathrm{NI} 7 \mathrm{I}-82 \mathrm{Q}$ mice (a) were robustly suppressed by co-treatment with both drugs starting at 7 weeks of age (b). Monotherapy with lithium or VPA showed a trend to ameliorate, whereas the effect did not reach statistical significance except the effect of lithium alone at 18 weeks of age (c). Regression analysis revealed no correlation between rotarod performance and body weight $(P=0.31$ ।; d). The motor skill learning of $\mathrm{NI} 7 \mathrm{I}-82 \mathrm{Q}$ mice, as measured by slopes of the rotarod performance across the 4-day trials, was similar to that of their wild-type littermates at 6 weeks of age (e). The motor skill learning of untreated NI7I-82Q mice (normalized by the slope obtained from agematched wild-type littermates) declined with age, and these decreases were significantly improved by co-treatment with lithium and VPA (f). $* P<0.05$, **P<0.0I, compared with corresponding wild-type or control groups. Data are mean $\pm \operatorname{SEM}(n=5-16)$.

co-treatment with lithium and VPA dramatically rescued this motor learning deficit in N171-82Q mice compared with control groups, and this effect persisted until the age of 22 weeks $(P<0.05$, $t$-test; Figure $3 f)$. Taken together, the results indicate that motor impairment in HD mice was significantly and robustly ameliorated by co-treatment with lithium and VPA compared with the effects of either drug alone, suggesting additive or synergistic neuroprotective effects.

\section{Lithium-VPA Co-Treatment Suppresses the Anxiety-Like Phenotype of YAC128 Mice}

In addition to motor disturbance and cognitive impairment, psychiatric disturbances including anxiety and depression are also highly prevalent in patients with HD (Di et al,
1993), and these psychological symptoms have profound implications for daily functioning and quality of life (Hamilton et al, 2003; Wheelock et al, 2003). However, these features are less emphasized in clinical and preclincial animal studies. To assess the potential effects of drug treatment on emotional changes, we studied anxiety-like and depressive-like behaviors in these two mouse models of HD.

Anxiety-like behaviors were measured by assessing time spent in the center region and in the open quadrants of the open-field and the elevated zero-maze tests, respectively. These parameters are inversely related to the degree of anxiety (Crawley, 1985; Shepherd et al, 1994). Despite the progressive decrease in locomotor activity, the time that N171-82Q mice spent in the center region of the open field did not differ from their wild-type littermates, and co-treatment with lithium and VPA that rescued locomotor deficits also had no effect on anxiety-like measures (data not shown). Consistently, the time that 22-week N171-82Q mice spent in the open quadrants of the elevated zero-maze did not differ from their wild-type littermates, regardless of drug treatment (data not shown). Therefore, the N171-82Q mouse model of HD appeared not to display an anxiety-like phenotype.

Consistent with a recent study showing that YAC128 mice do not exhibit anxiety-like behaviors at ages 3 to 4 months (Pouladi et al, 2009), the time that YAC128 mice spent in the center region of the open field did not differ from their wildtype littermates at 3 months (Figure 4a). However, a two-way ANOVA (genotype $\times$ age) revealed significant effects of genotype $(\mathrm{F}(1,95)=31.90, P<0.0001)$ and age $(\mathrm{F}(3,95)=13.48$, $P<0.0001)$. The time that YAC128 mice spent in the center region gradually decreased and differed significantly from age-matched wild-type littermates at 6, 9, and 12 months of age (Figure $4 \mathrm{a}$ ), suggesting increased levels of anxiety.

These anxiety-like behaviors were not suppressed by long-term treatment with either lithium or VPA alone, but were significantly inhibited by co-treatment with both drugs beginning at 3 months of age (Figure 4c). Under this co-treatment regimen, no significant difference was noted between wild-type and transgenic HD mice (Figure 4b). Although locomotor activities in YAC128 mice at corresponding ages were also decreased as described above, the untreated mice did show a preference and traveled primarily in the peripheral region of the open field compared with age-matched wild-type littermates and with those mice co-treated with lithium and VPA (Figure 4d). Therefore, anxiety differences should be reflected by the proportion of time spent in the center region of the open field. To confirm this observation in the open-field test, the anxiety-like behavior and the anxiolytic-like effects of drug treatment in YAC128 mice were measured via the elevated zero-maze test at 6 months of age. Consistent with the results of the open-field test, YAC128 mice in the control group spent less time in the open quadrants compared with their wild-type littermates (Figure 4e). However, monotherapy with either lithium or VPA - which had no effect in the open-field test-sufficed to suppress anxiety-like behaviors measured in the elevated zero-maze test. Co-treatment with lithium and VPA did not further enhance the anxiolyticlike effect. These results indicate a different sensitivity associated with these tests, and suggest that drug treatment in HD animal models can have anxiolytic-like effects. Co-treatment 

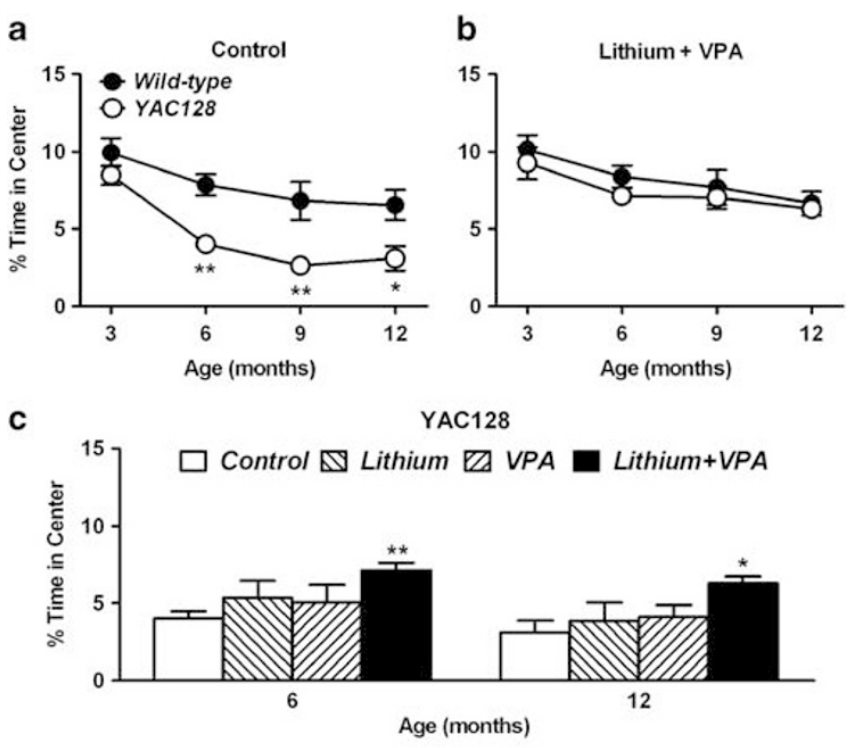

d

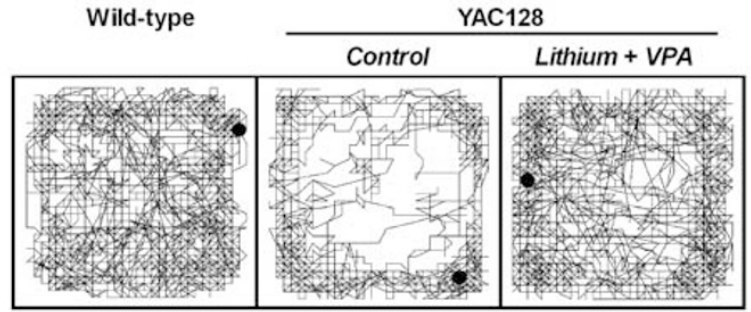

e

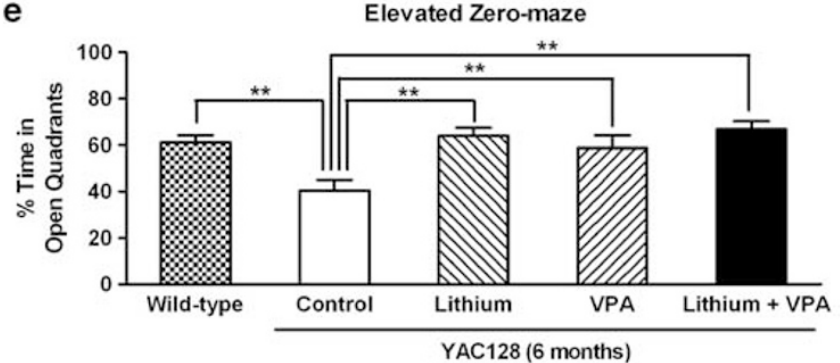

Figure 4 Co-treatment with lithium and VPA produces anxiolytic-like effects in YACI 28 mice. YACI 28 mice spent less time in the center region of the open field than their age-matched wild-type littermates (a), and these reductions were significantly inhibited by co-treatment with lithium and VPA (b), rather than treatment with each individual drug alone starting at 3 months of age (c). The representative traces of mice traveling in the open field at 6 months indicate the preference of untreated YACI 28 mice for the peripheral region of the open field, compared with wild-type and drug co-treated YACI 28 mice. The dot in each panel indicates the final position of the individual mouse in the open-field test (d). The decreased time spent by the YACI 28 mice in the open quadrants of the elevated zero-maze was prevented by lithium, VPA, or co-treatment with both drugs (e). $* P<0.05, * * P<0.01$, compared with corresponding wild-type or control groups. Data are mean \pm SEM $(n=8-16)$.

of lithium and VPA was the only effective treatment regimen in the open-field test, further implicating its more powerful anxiolytic-like effect in YAC128 mice.

\section{Co-Treatment with Lithium and VPA Produces Stronger Antidepressant-Like Effects in HD Mice}

Depressive-like behaviors in the HD mouse models of HD were measured and quantified by immobility time in the
FST and TST, in which longer immobility times are thought to reflect higher levels of depression.

In the FST, the immobility time of N171-82Q mice did not differ from their wild-type littermates at 6 weeks, but increased progressively with time. Two-way ANOVA (genotype $\times$ age) revealed significant effects of genotype $(\mathrm{F}(1,58)=28.14, \quad P<0.0001)$ and age $(\mathrm{F}(4,58)=3.00$, $P=0.0255)$, and the immobility times of N171-82Q mice were significantly longer than those of their age-matched wild-type littermates at 14, 18, and 22 weeks (Figure 5a; Bonferroni post test), indicating increased levels of depressive-like behaviors. In the FST, long-term treatment with lithium, VPA, or both drugs together all decreased immobility time in N171-82Q mice, but the effects did not reach statistical significance until 22 weeks (Figure $5 \mathrm{~b}$ ). In the TST, the treatment of N171-82Q mice with lithium alone or lithium plus VPA produced obvious antidepressant-like effects at 18 and 22 weeks of age, whereas treatment with VPA alone did not (Figure 5e). Co-treatment with lithium and VPA produced the earliest effects (14 weeks).

Unlike the N171-82Q model and in contrast to the ate-developing motor deficits, YAC128 mice exhibited depressive-like behaviors before the onset of any motor symptoms. These deficits were evident at 3 months of age, as revealed and confirmed by increased immobility in the FST and TST, respectively. Two-way ANOVA (genotype $\times$ age) showed significant effects of genotype $(\mathrm{F}(1,74)=31.45, \quad P<0.0001)$ and age $(\mathrm{F}(2,74)=12.14$, $P<0.0001)$, and these depressive-like behaviors were longlasting and sustained throughout the tested time frame of 12 months of age (Figure $5 \mathrm{c}$; Bonferroni post test). In the FST, long-term treatment with lithium, VPA or both drugs together, starting at 3 months of age, had comparable antidepressant-like effects when measured at 6 and 12 months of age (Figure 5d). Similarly, increased immobility in the TST was suppressed by long-term treatment with lithium, or with lithium and VPA co-treatment (Figure 5f). Taken together, these data indicate that lithium has stronger antidepressant-like properties than VPA in HD mice, and that lithium's effects, at least in 14-week N171-82Q mice, appear to be enhanced by co-treatment with VPA.

\section{Co-Treatment with Lithium and VPA Decreases GSK-3 $\beta$ Activity in the Brains of HD Mice}

Dysfunction of GSK-3, a serine/threonine protein kinase consisting of $\alpha$ - and $\beta$-isoforms, has been implicated in the pathophysiology of many neuropsychiatric disorders (for review, see Beurel et al, 2010; Huang and Klein, 2006; Jope et al, 2007). Activation of this kinase has also been linked to apoptotic cell death induced by multiple insults, including glutamate excitotoxicity (Grimes and Jope, 2001). Accumulating evidence suggests that GSK-3 inhibition is one of the critical targets for lithium's multiple neuroprotective effects (for review, see Chiu and Chuang, 2010; Rowe and Chuang, 2004; Rowe et al, 2007). In addition, the synergistic neuroprotective effects of lithium and VPA co-treatment in vitro were found to be due, at least in part, to enhanced inhibition of this kinase (Leng et al, 2008). Therefore, we first examined the activity of GSK-3 isoform $\beta$ (GSK-3 $\beta$ ) in the brains of $\mathrm{HD}$ mice to determine the potential 

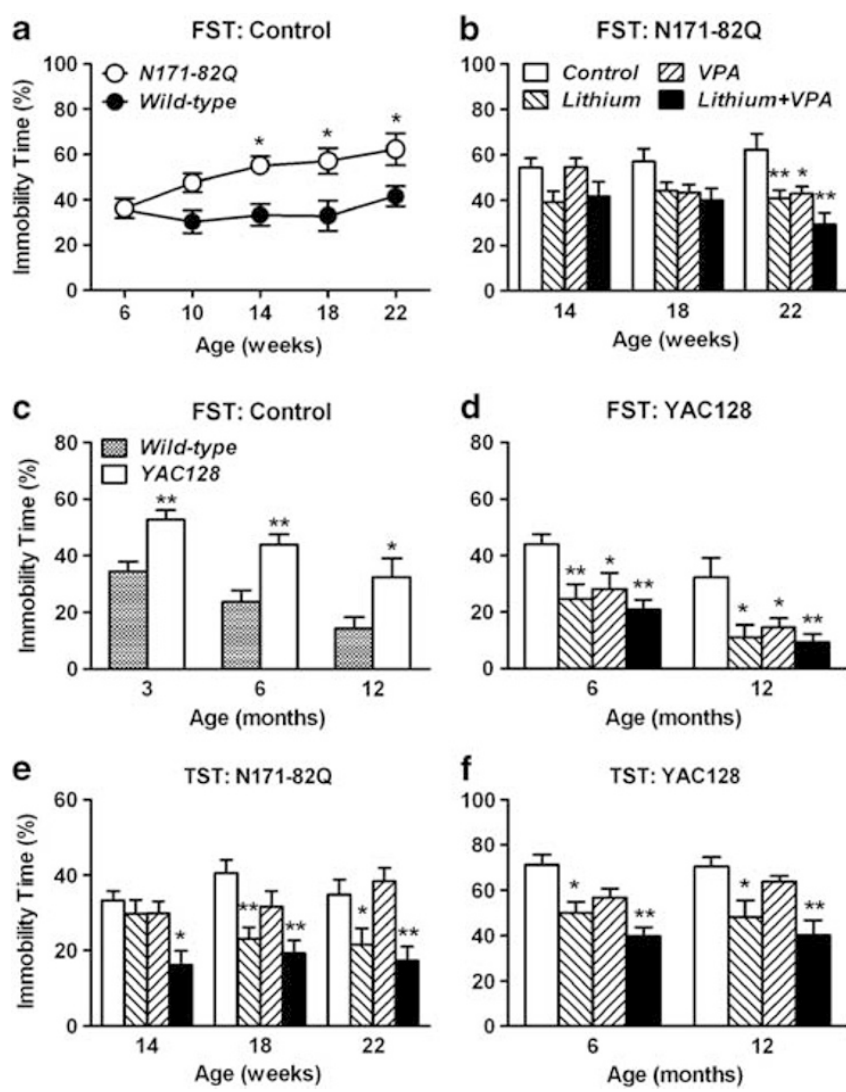

Figure 5 Lithium-VPA co-treatment produces stronger antidepressantlike effects in HD mice. The depressive-like behaviors of NI7I-82Q mice, as assessed by increased immobility time in the FST (a), were significantly suppressed at 22 weeks by long-term treatment with lithium, VPA, or cotreatment with both drugs (b). YACI28 mice showed depressive-like behaviors at a relatively young age (3 months), as assessed by increased immobility time in the FST (c). Long-term treatment with lithium, VPA, or both drugs together starting at 3 months of age significantly suppressed the increased immobility time at 6 and 12 months (d). The antidepressant-like effects of drug treatment were further confirmed by the TST. In N I 7 -82Q mice, treatment with VPA alone was ineffective, whereas the effects of lithium alone or co-treatment with both drugs were significant at the earlier time points of 18 and 14 weeks of age, respectively, compared with those in the FST (e). The depressive-like behaviors of YACI28 mice were significantly suppressed by treatment with lithium alone or lithium plus VPA, but not VPA alone (f). $* P<0.05$, $* * P<0.01$, compared with corresponding wild-type or control groups. Data are mean \pm SEM $(n=6-16)$.

biochemical mechanisms underlying the multiple behavioral benefits of co-treatment with lithium and VPA.

GSK- $3 \beta$ activity in the cortex and striatum of HD mice was measured by phosphorylation of this kinase at the specific Ser9 residue. Phosphorylation at this residue negatively regulates GSK-3 $\beta$ activity (Chalecka-Franaszek and Chuang, 1999; De Sarno et al, 2002; Zhang et al, 2003). Long-term treatment of N171-82Q mice for 2 to 4 weeks with either lithium, VPA, or both drugs, starting at 7 weeks of age, did not affect the expression of GSK $-3 \beta$ mRNA in the cortex or striatum (Figure $6 \mathrm{a}$ ). GSK-3 $\beta$ mRNA expression was also not altered in these brain regions in YAC128 mice receiving these drug treatments starting at 3 months of age (Figure 6b). These drug treatments consistently failed to alter protein levels of total GSK-3 $\beta$ (T-GSK-3 $\beta$ ) in the brains of these HD mice even after 8 weeks of treatment (upper panels; Figures $6 \mathrm{c}$ and d). Compared with wild-type littermates, no alteration in the expression of T-GSK-3 $\beta$ protein was observed in the brains of untreated N171-82Q and YAC128 mice throughout the time frame measured (from 11 to 22 weeks and 4 to 6 months of age, respectively; Figures $6 e$ and $f$ ).

The levels of GSK-3 $\beta$ phosphorylation at the Ser9 residue $(\mathrm{P}-\mathrm{GSK}-3 \beta)$ in the cortex and striatum of untreated N171-82Q and YAC128 did not differ significantly from their wild-type littermates at 11 weeks and 4 months of age, respectively. However, they were decreased with time when measured at 22 weeks and 6 months of age, respectively, indicating an increase in GSK-3 $\beta$ activity in the brains of HD mice (Figures 6e and $\mathrm{f}$ ). Phosphorylation of GSK-3 $\beta$ in these brain regions of both N171-82Q and YAC128 mice rapidly increased after treatment with lithium alone for 2 weeks and, to a lesser extent, treatment with VPA alone for an extended period of time (Figures $6 \mathrm{c}$ and $\mathrm{d}$ ). Compared with the effect produced by lithium monotherapy, VPA co-administration elevated GSK-3 $\beta$ phosphorylation levels more significantly and consistently in both brain regions of the two $\mathrm{HD}$ models, suggesting a sustained inhibition of this kinase by this combined treatment (Figures $6 \mathrm{c}$ and $\mathrm{d}$ ).

\section{Co-Treatment with Lithium and VPA Increases Histone $\mathrm{H} 3$ Acetylation in the Brains of HD Mice}

At clinically relevant levels, VPA has been shown to inhibit HDACs (Göttlicher et al, 2001; Phiel et al, 2001). HDAC inhibition reduces histone deacetylation, thereby keeping chromatin in a relaxed conformation, and facilitating the access of transcription factors and RNA polymerase to the promoter of a specific gene and resulting in transcriptional activation. To determine whether co-treatment with lithium potentiated the effects of VPA on HDAC inhibition, we next examined the acetylation levels of histone H3 at Lys9 and Lys 14 in the brains of HD mice receiving drug treatment.

In the cortex and striatum of untreated N171-82Q and YAC128 mice, the levels of histone $\mathrm{H} 3$ acetylation did not differ significantly from their wild-type littermates at 11 weeks and 4 months, but were decreased at 22 weeks and 6 months of age, respectively (Figures $7 \mathrm{c}$ and $\mathrm{d}$ ). As expected, histone $\mathrm{H} 3$ acetylation levels were rapidly increased in these brain regions of N171-82Q mice treated with VPA alone for 2 weeks, suggesting HDAC inhibition (Figure 7a). Although lithium monotherapy for 2 weeks was ineffective, histone $\mathrm{H} 3$ acetylation levels in these brain regions were also markedly enhanced after 4 weeks of lithium treatment. Cotreatment with both VPA and lithium only slightly, and not significantly, elevated histone H3 acetylation levels compared with 8 weeks of VPA monotherapy. Similar results were observed in the cortex and striatum of YAC128 mice after 2 to 8 weeks of drug treatment starting at 3 months of age (Figure $7 \mathrm{~b}$ ).

\section{Co-Treatment with Lithium and VPA Enhances BDNF Levels in the Brains of HD Mice}

BDNF is an essential pro-survival neurotrophin for striatal neurons (Nakao et al, 1995; Ventimiglia et al, 1995), has 
a

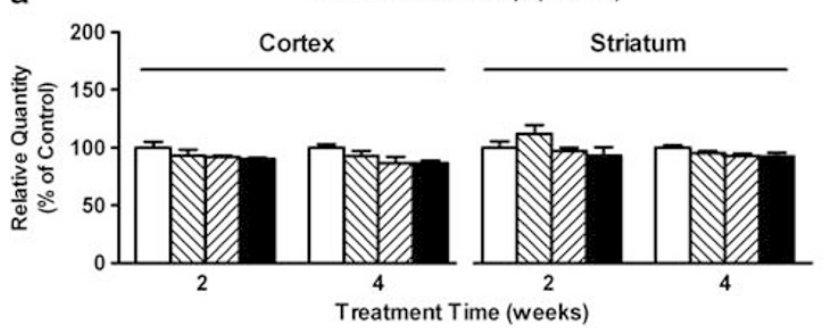

b

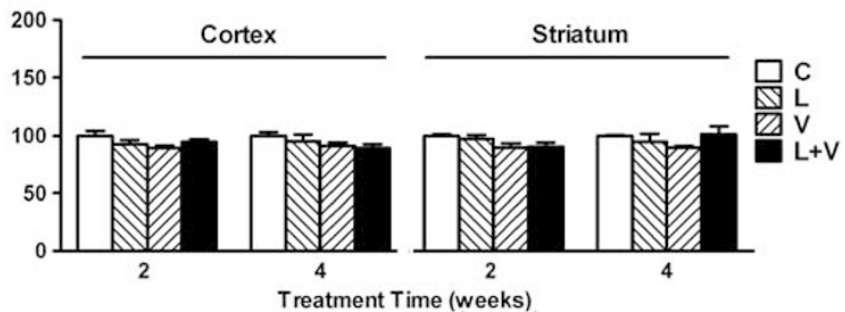

c
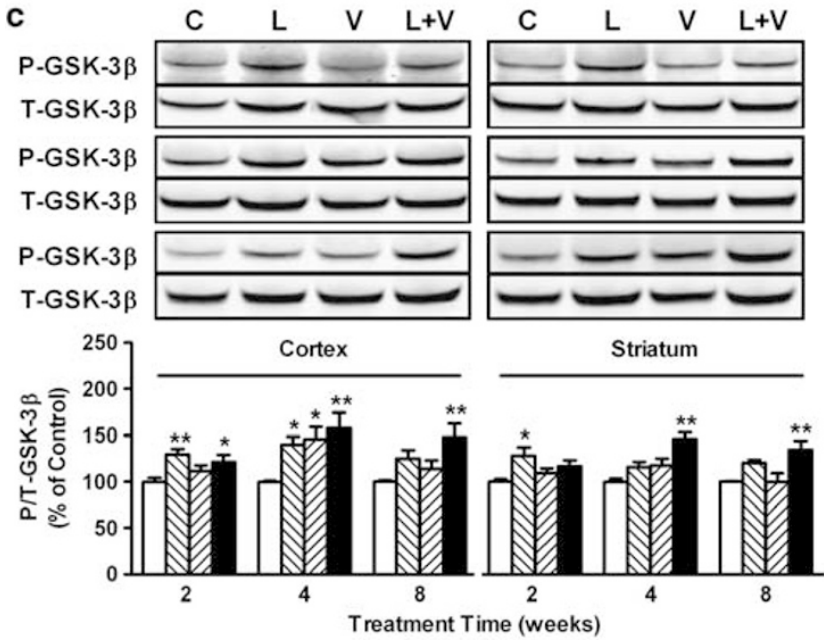

e

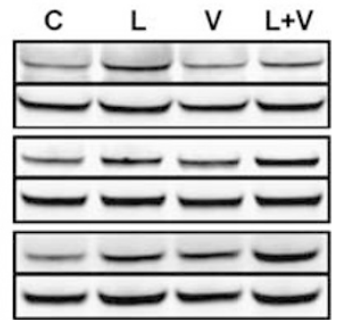

d
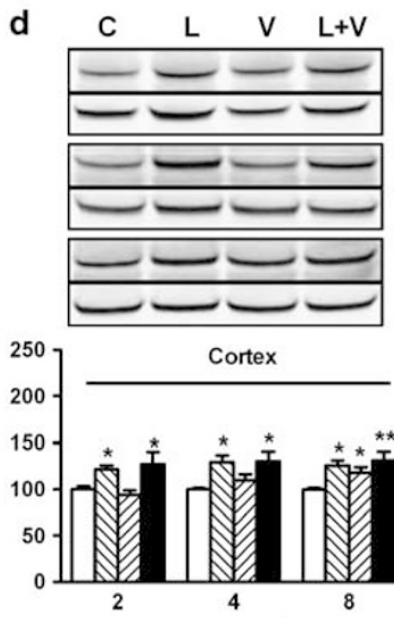

Cortex

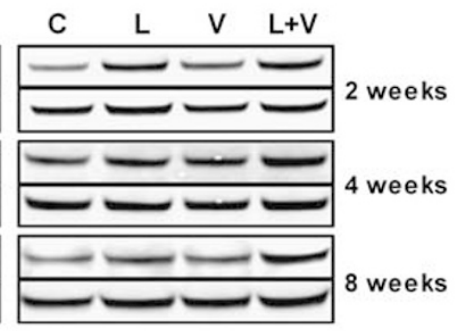

Striatum

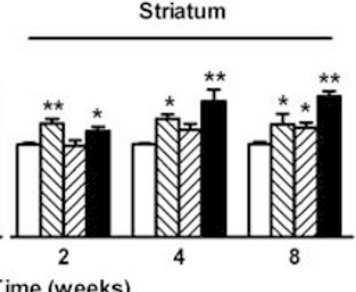

f

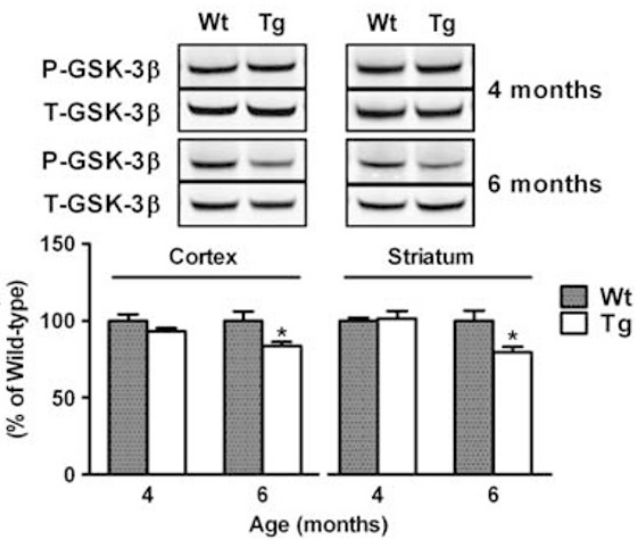

Figure 6 Co-treatment with lithium and VPA increases GSK-3 $\beta$ phosphorylation levels in the brains of HD mice. GSK-3 $\beta$ mRNA expression was measured by quantitative real-time PCR in the cortex and striatum of NI7I-82Q (a) and YACI 28 mice (b) after 2 and 4 weeks of dietary treatment with lithium, VPA, or both drugs. Total GSK-3 $\beta$ protein (T-GSK-3 $\beta$ ) levels, as well as phosphorylation at the Ser9 residue (P-GSK-3 $\beta$ ) in these brain regions of NI7I-82Q (c) and YACI28 mice (d) were measured by western blotting analysis after 2 to 8 weeks of drug treatment. The levels of GSK-3 $\beta$ phosphorylation in these brain regions of untreated NI7I-82Q (e) and YACI 28 mice (f) did not differ significantly from their wild-type littermates at II weeks and 4 months, but were decreased at 22 weeks and 6 months of age, respectively. Typical western blots with quantified results (expressed as P-GSK$3 \beta / T$-GSK-3 $\beta$ ) are shown. $* P<0.05$, $* * P<0.01$, compared with corresponding control or wild-type groups. Data are mean $\pm S E M$ of percentage of control $(n=4-8)$. C, control; L, lithium; L + V, lithium + VPA; Tg, transgenic HD mice; V, VPA; Wt, wild-type mice.

a central role in cortical development and synaptic plasticity, and is likely a key mediator of the clinical efficacy of antidepressants and anxiolytic drugs (for review, see Woo and $\mathrm{Lu}, 2006$ ). A previous study from our laboratory demonstrated that lithium and VPA, by inhibiting GSK-3 $\beta$ and HDACs, respectively, activate BDNF promoter IV in cortical neurons (Yasuda et al, 2009). Long-term treatment with lithium or VPA has also been shown to increase BDNF expression in the rat brain (Fukumoto et al, 2001). We therefore sought to determine whether BDNF is one of the downstream mediators underlying the behavioral benefits produced by co-treatment with lithium and VPA.

Compared with monotherapy with either lithium or VPA alone, long-term co-treatment with both agents significantly and consistently elevated BDNF mRNA levels in the cortex and striatum of N171-82Q (Figure $8 \mathrm{a}$ ) and YAC128 mice (Figure 8b). BDNF protein levels were also consistently, rapidly, and markedly elevated by co-treatment with lithium and VPA in these two brain regions in both HD models (Figures $8 \mathrm{c}$ and $\mathrm{d}$ ). In the striatum of both strains of $\mathrm{HD}$ 
a

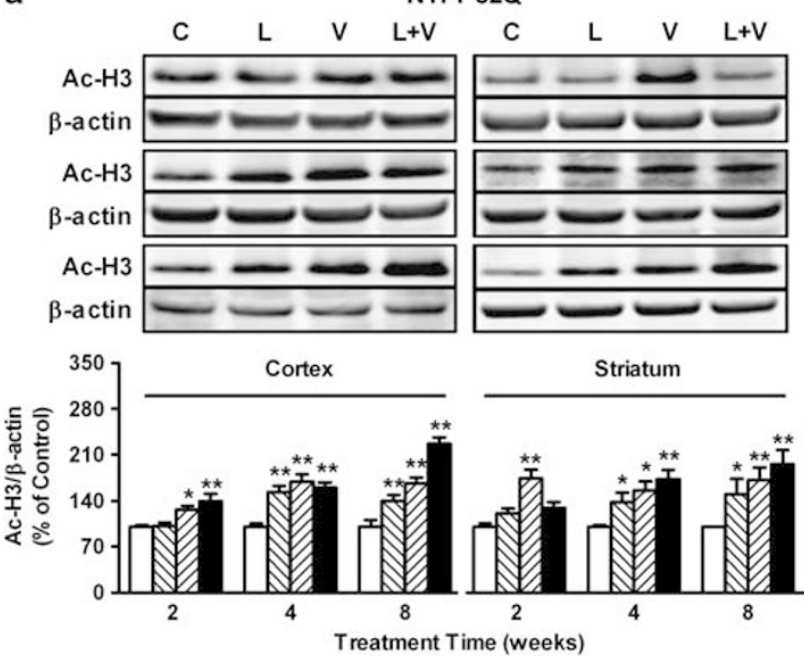

C

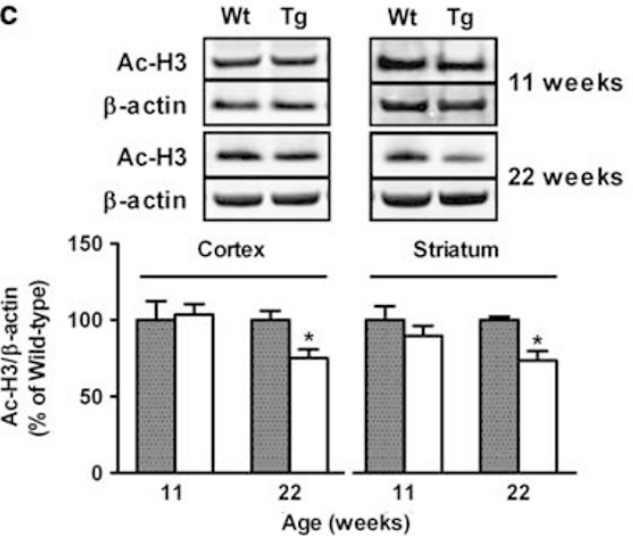

b

YAC128
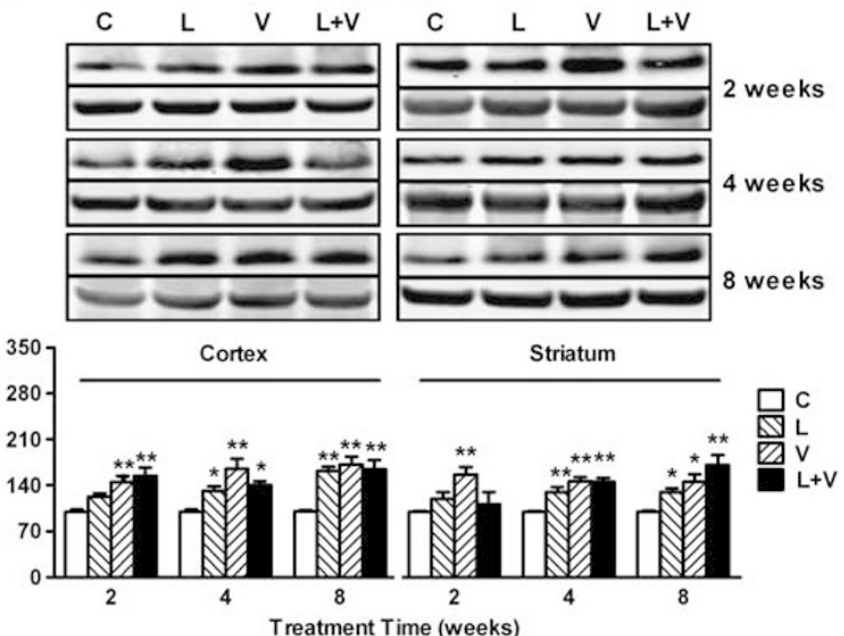

d

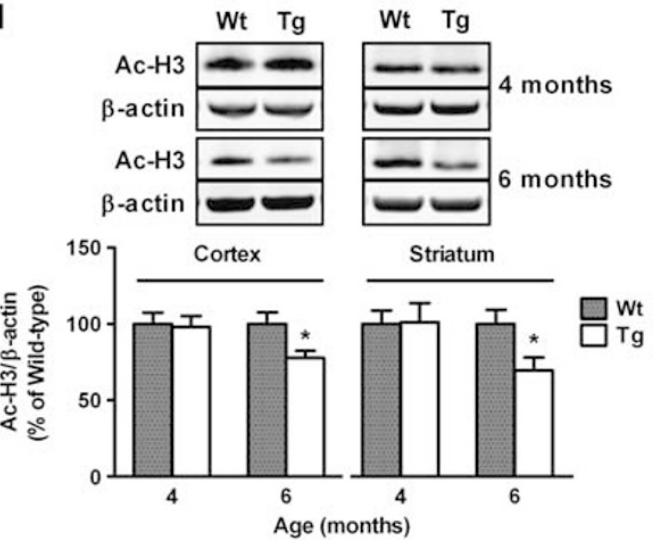

Figure 7 Co-treatment with lithium and VPA increases histone $\mathrm{H} 3$ acetylation in the brains of HD mice. The acetylation levels of histone H3 at Lys9 and Lys I 4 residues in the cortex as well as striatum of $\mathrm{NI} 7 \mathrm{I}-82 \mathrm{Q}$ (a) and YACI 28 mice (b) were measured by western blotting analysis after 2 to 8 weeks of dietary treatment with lithium, VPA, or both drugs. The levels of histone $\mathrm{H} 3$ acetylation in these brain regions of untreated NI 7I-82Q (c) and YACI 28 mice (d) did not differ significantly from their wild-type littermates at I I weeks and 4 months, but were decreased at 22 weeks and 6 months of age, respectively. $\beta$-Actin was used as a loading control. Typical western blots with quantified results (expressed as Ac-H3/ $\beta$-actin) are shown. $* P<0.05$, *** $P<0.0 \mathrm{I}$, compared with corresponding control or wild-type groups. Data are mean \pm SEM of percentage of control $(n=4-8)$. C, control; $L$, lithium; $L+V$, lithium $+V P A$; $\mathrm{Tg}$, transgenic HD mice; V, VPA; Wt, wild-type mice.

mice, lithium or VPA monotherapy for 2 weeks did not increase BDNF protein levels unless both drugs were coadministered. In addition, activation of tyrosine receptor kinase B (TrkB), the cell-surface receptor of BDNF, has been identified as an obligatory event for the neuroprotective effects of lithium in vitro (Hashimoto et al, 2002). Here, we found that long-term co-treatment with lithium and VPA also significantly enhanced $\operatorname{TrkB}$ transcript levels in the brains of these HD mice (Figures $8 \mathrm{e}$ and $\mathrm{f}$ ).

\section{Co-Treatment with Lithium and VPA Upregulates HSP70 Expression in the Brains of HD Mice}

HSPs are molecular chaperones that promote protein folding, inhibit aggregate formation, and facilitate degradation of abnormally folded proteins through the ubiquitinproteasome system (Fink, 1999; Hartl and Hayer-Hartl, 2002). Previous studies from our laboratory demonstrated that treatment with either lithium or VPA alone increases HSP70 expression in cultured neurons and rats subjected to cerebral ischemia (Kim et al, 2007; Marinova et al, 2009; Ren et al, 2003, 2004). To further examine whether HSP70 is another potential downstream mediator behind the beneficial effects of co-treatment with lithium and VPA, we measured alterations of this protein in the brains of HD mice.

In the cortex and striatum of N171-82Q and YAC128 mice, treatment with VPA alone increased HSP70 mRNA (Figures 9a and b) and protein levels (Figures 9c and d) more than treatment with lithium alone. Compared with the effects produced by VPA monotherapy, co-administration of lithium elevated HSP70 transcript and protein levels more rapidly and consistently in both models of HD. In the cortex of both HD mice, monotherapy with lithium or VPA for 2 weeks did not increase HSP70 protein levels; however, co-treatment with both agents did increase HSP70 levels. In addition to BDNF and HSP70, transcript levels of the cytoprotective protein B-cell lymphoma/leukemia-2 were also consistently increased by co-treatment with lithium and VPA in the brains of both models of HD (Figures 9e and $\mathrm{f}$ ). 
a

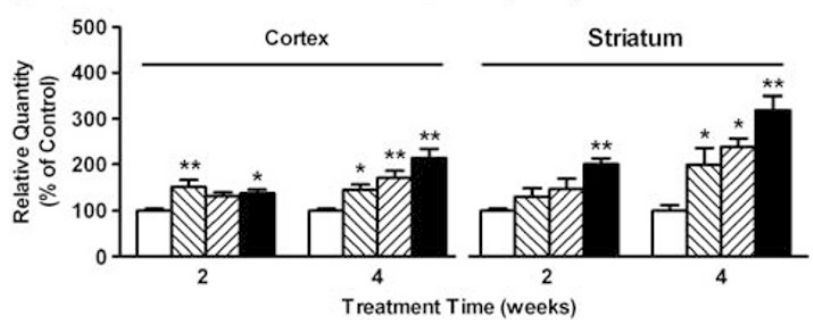

C
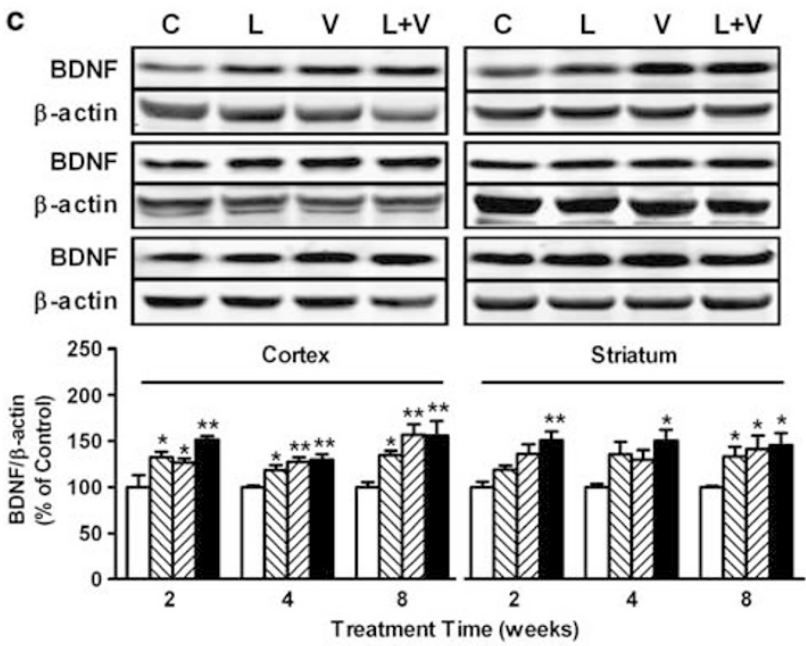

e

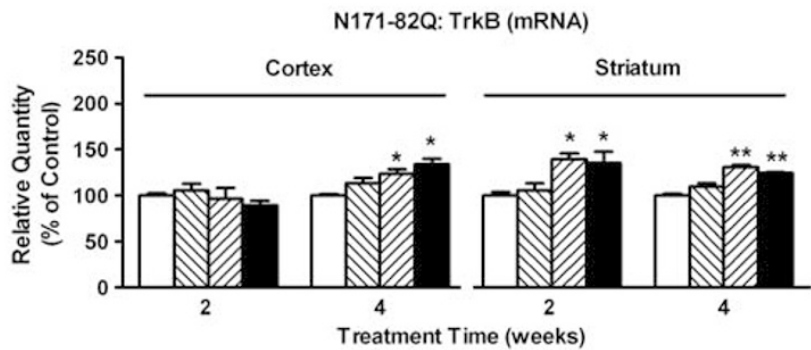

b

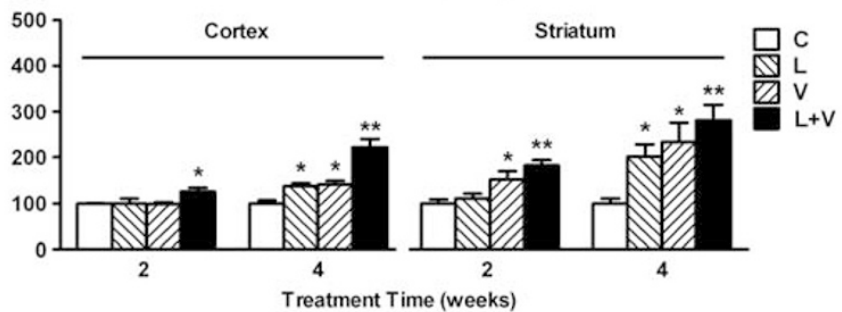

d
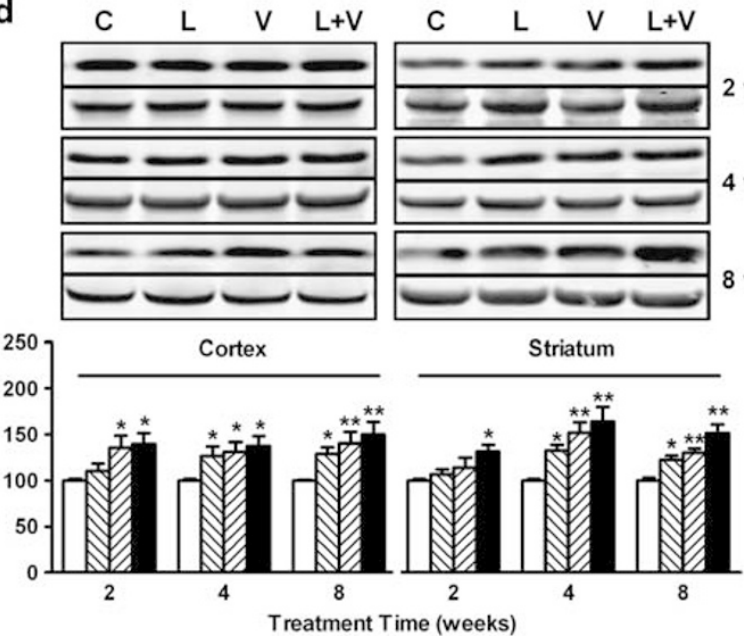

$f \quad$ YAC128: TrkB (mRNA)

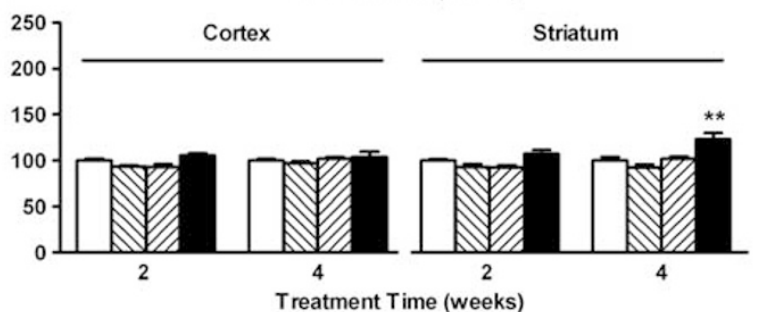

Figure 8 Co-treatment with lithium and VPA enhances BDNF levels and TrkB transcript levels in the brains of HD mice. BDNF mRNA expression was measured by quantitative real-time PCR in the cortex and striatum of NI7I-82Q (a) and YACI 28 mice (b) after 2 and 4 weeks of dietary treatment with lithium, VPA, or both drugs. Expression of mature BDNF protein in these brain regions of NI 7I-82Q (c) and YACI28 mice (d) was measured by western blotting analysis after 2 to 8 weeks of drug treatment. $\beta$-Actin was used as a loading control. Typical western blots with quantified results (expressed as $\mathrm{BDNF} / \beta$-actin) are shown. Expression of TrkB mRNA was measured by quantitative real-time PCR in the cortex and striatum of NI7I-82Q (e) and YACI 28 mice ( $f$ ) after 2 and 4 weeks of dietary treatment with lithium, VPA, or both drugs. $* P<0.05$, *** $<0.0$ I, compared with corresponding control groups. Data are mean \pm SEM of percentage of control $(n=4-8)$. C, control; L, lithium; L + V, lithium + VPA; V, VPA.

Taken together, these data implicate multiple downstream mediators that might work collectively to elicit the beneficial behavioral effects seen with co-treatment.

\section{DISCUSSION}

This study investigated the putative benefits and potential underlying mechanisms of co-treatment with lithium and VPA in both N171-82Q and YAC128 mouse models of HD. These two mouse strains exhibit neurological and behavioral abnormalities similar to those found in human HD patients, but have different genetic backgrounds and pathological progressions (Schilling et al, 1999; Slow et al, 2003). We demonstrated that long-term co-treatment of these HD mice with lithium and VPA markedly increased the expression of several survival molecules in the brain, and more successfully suppressed motor deficits and psychiatric disturbances than treatment with either drug alone. These data are consistent with our recent studies showing that co-treatment with lithium and VPA not only has synergistic neuroprotective effects against glutamate excitotoxicity in cultured brain neurons (Leng et al, 2008), but also delays disease onset in a mouse model of amyotrophic lateral sclerosis (Feng et al, 2008).

Co-treatment with lithium and VPA augmented individual effects in alleviating spontaneous locomotor deficits and improving motor skill learning and coordination in HD mice. Accelerated rotarod training requires not only motor coordination but also the learning of task-related motor strategies (Buitrago et al, 2004). We measured rotarod performance only in N171-82Q mice, because a large variation 

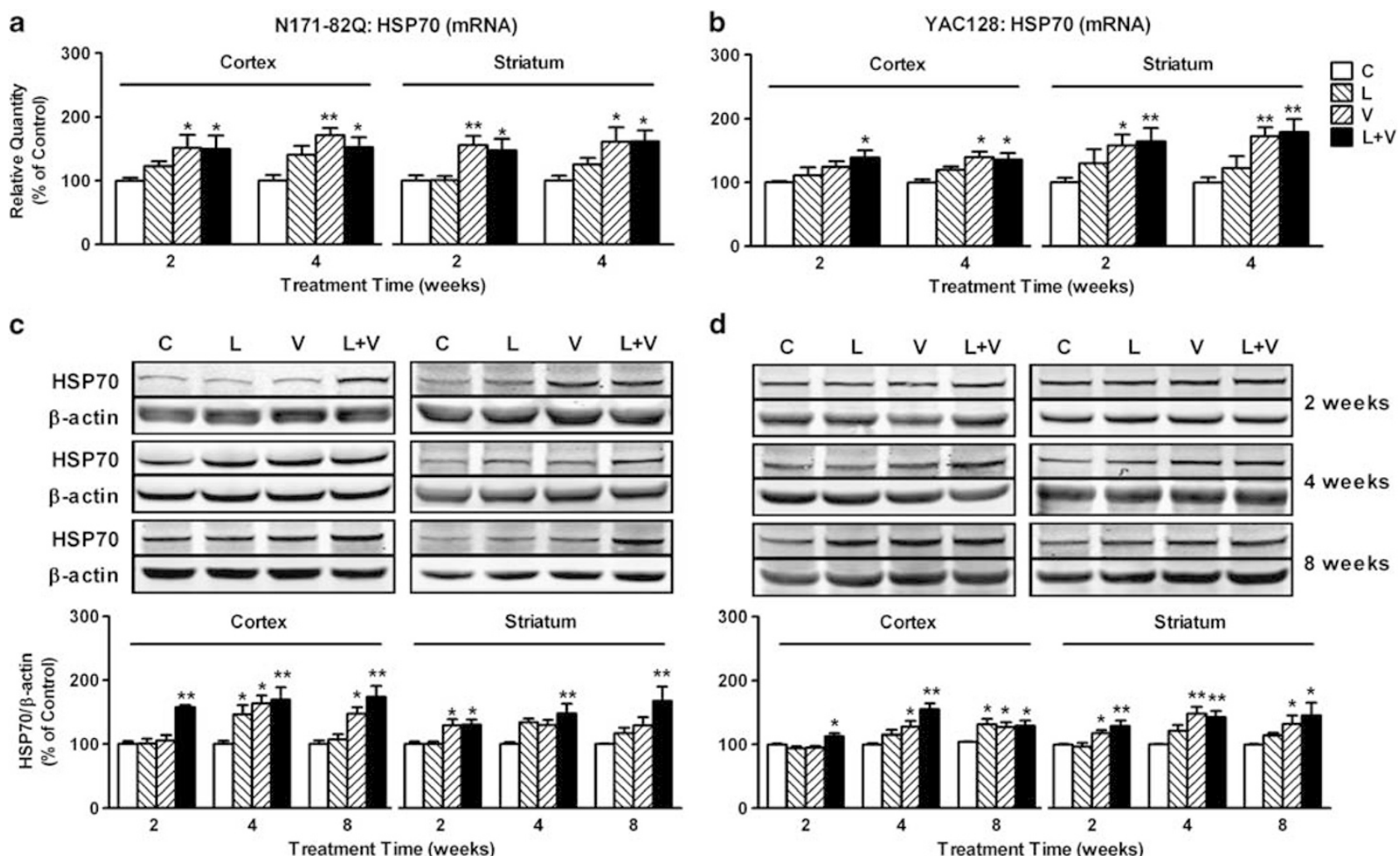

d

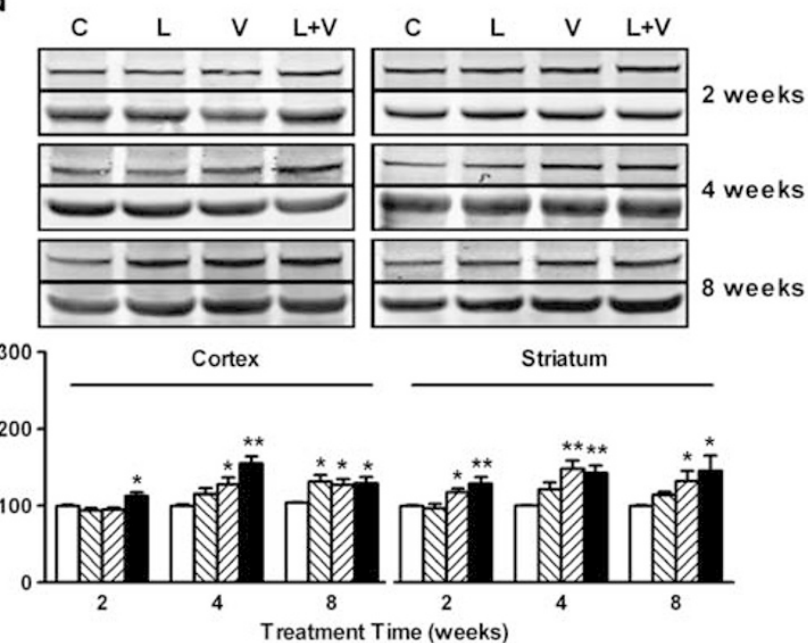

N171-82Q: Bcl-2 (mRNA)

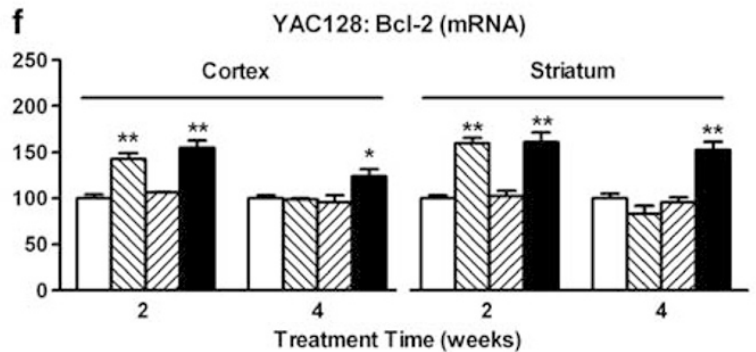

Figure 9 Co-treatment with lithium and VPA upregulates HSP70 expression and B-cell lymphoma/leukemia-2 (Bcl-2) transcript levels in the brains of HD mice. HSP70 mRNA expression was measured by quantitative real-time PCR in the cortex and striatum of NI7I-82Q (a) and YACI 28 mice (b) after 2 and 4 weeks of dietary treatment with lithium, VPA, or both drugs. HSP70 protein expression in these brain regions of NI7I-82Q (c) and YACI28 mice (d) was measured by western blotting analysis after 2 to 8 weeks of drug treatment. $\beta$-Actin was used as a loading control. Typical western blots with quantified results (expressed as HSP70/ $\beta$-actin) are shown. Bcl-2 mRNA expression was measured by quantitative real-time PCR in the cortex and striatum of $\mathrm{NI}$ II 82Q (e) and YACI 28 mice $(f)$ after 2 and 4 weeks of dietary treatment with lithium, VPA, or both drugs. $* P<0.05$, *** $P<0.01$, compared with corresponding control groups. Data are mean \pm SEM of percentage of control $(n=4-8)$. C, control; $L$, lithium; $L+V$, lithium $+V P A ; ~ V, V P A$.

was observed in YAC128 mice despite a reported rotarod deficit in this strain (Slow et al, 2003). Improved rotarod performance in N171-82Q mice was not a secondary effect of weight loss, as these variables were not correlated (Figure 3d). It is also unlikely that the improved rotarod performance noted with co-treatment was due to druginduced improvements in general locomotor activity, as locomotor impairment in N171-82Q mice was evident as early as 10 weeks of age (Figure 2a), whereas rotarod performance deficits were not significant until 18 weeks (Figure 3a).

The striatum has an important role in motor function and in the rotarod task (Carter et al, 1999), and affects complex cognitive tasks including memory and executive functions (Tekin and Cummings, 2002). In HD, mutant huntingtin causes substantial degeneration of medium-sized spiny neurons in this brain region (MacDonald et al, 1993; Rubinsztein, 2002; Vonsattel and DiFiglia, 1998). Therefore, it seems possible that improved motor function in HD mice could be attributable to the neuroprotective effect of co-treatment with lithium and VPA. Past studies have indicated that lithium or VPA monotherapy protects against mutant huntingtin-induced toxicity in various HD models with mixed efficacy (Carmichael et al, 2002; Wood and Morton, 2003; Zadori et al, 2009). In our study, cotreatment with lithium and VPA produced more rapid and sustained inhibition of GSK-3 $\beta$ and HDACs than monotherapy. Inhibition of GSK-3 $\beta$ and HDACs is known to mediate induction of neuroprotective and/or neurotrophic proteins and protects against diverse insults in vitro and in vivo (for review, see Beurel et al, 2010; Chuang et al, 2009; Rowe and Chuang, 2004; Rowe et al, 2007). However, the 
median survival time of VPA-treated mice was prolonged from 37.36 to 41.57 weeks by co-treatment with lithium; this effect did not reach statistical significance. It should be noted that the serum concentration of lithium treatment is near the top edge of therapeutic levels for human bipolar patients. Given that lithium has a narrow therapeutic margin, and the beneficial dose range for humans might not be identical to that for mice, we suspect that benefits produced by lithium treatment may be weakened or masked by a small increase over its therapeutic range. The neuroprotective effects of co-treatment against neurodegeneration in the brains of HD mice are currently under investigation.

Anxiety is a frequent psychiatric symptom in HD patients, but not a universal phenotype in all animal models of this disease. For example, YAC128 mice showed increased anxiety-like behaviors in our study, but others have noted decreased anxiety in the R6/2 model of HD (File et al, 1998). Consistent with previous observations (Klivenyi et al, 2006), N171-82Q mice in this study expressed no anxiety-like behaviors. The disparity between models may be attributed to differences in the size of the polyQ stretch, the rate of pathology progression, or genetic backgrounds, as recently suggested (Hickey et al, 2008; Klivenyi et al, 2006). Compared with the open-field paradigm, the elevated zero-maze test is a modified, more sensitive method of measuring anxiety-like behaviors (Shepherd et al, 1994). This may explain our observation that lithium or VPA alone was ineffective in the open-field test. However, the fact that the anxiolytic-like effects of co-treatment with lithium and VPA were demonstrated by this less sensitive test suggests a stronger effect of co-treatment, which might have been obscured by ceiling effects in the more sensitive elevated zero-maze paradigm.

We also used the FST and TST to evaluate depressive-like behaviors. Hyperactivity has been reported to affect immobility and lead to false-positive results in the FST (Porsolt et al, 1977), whereas the TST appears to be more relevant for the study of animals with compromised motor coordination (for review, see Cryan and Mombereau, 2004; Cryan et al, 2005). Here, we found that treatment with lithium or VPA alone decreased the immobility time of N171-82Q mice in the FST (Figure 5b), without significantly affecting their locomotor activity at 22 weeks (Figure 2c). Similar results were observed in YAC128 mice assessed at 6 and 12 months of age (Figures $2 \mathrm{f}$ and $5 \mathrm{~d}$ ). The ability of YAC128 mice to swim was not impaired at ages up to 12 months (Pouladi et al, 2009), while locomotor activity was markedly decreased (Figure 2d). In addition, the increased locomotor activity resulting from co-treatment with lithium and VPA did not significantly influence immobility time in N171-82Q mice at 14 and 18 weeks of age in the FST (Figure 5b). Therefore, the reduced immobility of HD mice in the FST was not likely to result from increased locomotor activity induced by co-treatment. Of note, forced swimming is sometimes considered a major stressor that suppresses general behavioral activity in mice (Liaw et al, 1998), whereas the TST is more sensitive and used to detect the effects of a broad spectrum of antidepressants (Cryan and Mombereau, 2004). Accordingly, the antidepressant-like effects of lithium alone as well as co-treatment with lithium and VPA in N171-82Q mice could be revealed by the TST at much earlier ages (ie, 14 and 18 weeks) than those revealed by the FST at 22 weeks.

Lithium has been shown to enhance the synthesis and release of serotonin (Sangdee and Franz, 1978; Treiser et al, 1981), and to demonstrate antidepressant-like effects in animal studies employing the FST (Bersudsky et al, 2007; O'Brien et al, 2004) and TST (Gould et al, 2008). These effects likely involve GSK-3 inhibition. Using pharmacological or genetic approaches, GSK-3 $\beta$ inhibition has been found to alleviate depressive behaviors in experimental animals (Beaulieu et al, 2008; Gould et al, 2004; Kaidanovich-Beilin et al, 2004; Omata et al, 2011; Rosa et al, 2008). VPA, an anticonvulsant drug with anxiolytic properties (de Angelis, 1992), has also been shown to inhibit GSK-3 $\beta$ through phosphorylation at Ser9 residue under some in vitro conditions (Chen et al, 1999; De Sarno et al, 2002). These findings may explain our observation that co-treatment with lithium and VPA not only produced rapid and sustained GSK- $3 \beta$ inhibition, but also consistent and robust antidepressant-like effects in HD mice. On the other hand, HDAC inhibition by a VPA analog, sodium butyrate, has been found to potentiate the antidepressant-like effects of fluoxetine (Schroeder et al, 2007). The potentiation of VPA-induced HDAC inhibition by co-treatment with lithium suggests the involvement of epigenetic regulation in the antidepressant-like effects observed here.

Co-treatment with lithium and VPA also caused a more rapid and sustained elevation of both BDNF and HSP70 than monotherapy. Decreased BDNF has been reported in the striatum of human HD patients (Ferrer et al, 2000; Zuccato et al, 2001) as well as in animal models of HD (Duan et al, 2003, 2008). In addition, HSP70 and its cochaperone HSP40 were found to colocalize with huntingtin aggregates (Jana et al, 2000) and were decreased in the brains of HD animal models (Chiang et al, 2007; Duan et al, 2008; Hay et al, 2004; Yamanaka et al, 2008). Enhanced BDNF expression protects neurons from neurochemical insults associated with HD both in cultured cells (Saudou et al, 1998) and rodents (Bemelmans et al, 1999; Canals et al, 2004; Kells et al, 2004), while HSP overexpression not only reduces the formation of huntingtin aggregates but also suppresses neurodegeneration and toxicity associated with this disease (Chan et al, 2000; Fujimoto et al, 2005; Jana et al, 2000). Of particular relevance to the behavioral effects of co-treatment, BDNF is considered a key mediator of the clinical efficacy of antidepressants and anxiolytic drugs (Woo and Lu, 2006). Moreover, depressive-like behaviors in YAC128 mice resistant to chronic antidepressant treatment was ameliorated by preventing cleavage of mutant huntingtin (Pouladi et al, 2009), suggesting that the action of HSP70 on huntingtin aggregate clearance may have a role in the antidepressant-like effects of this co-treatment. Together, these results suggest that BDNF and HSP70 are likely downstream mediators involved in the observed behavioral improvements following co-treatment with lithium and VPA. Nonetheless, their therapeutic mechanisms remain unresolved, and lithium and VPA have many targets and multiple effects. Therefore, before further investigation, other potential targets of this combined treatment that may also contribute to the beneficial effects in HD certainly cannot be ruled out. 
In conclusion, the present results showed that co-treatment with lithium and VPA robustly and more consistently improves motor deficits and psychiatric disturbances in both mouse models of HD. These behavioral benefits are likely triggered by potentiated inhibition of GSK-3 $\beta$ and HDACs to induce critical molecules such as BDNF and HSP70. Given that both lithium and VPA have a long history of safe use in humans, and that the devastating symptoms of HD progressively intensify without remission until death, our data provide a strong rationale for using a combination of lithium and VPA to treat HD patients.

\section{ACKNOWLEDGEMENTS}

We thank Dr Michael Hayden and his colleagues of the Department of Medical Genetics, University of British Columbia, Vancouver, British Columbia, Canada, for consultation and assistance in resolving issues surrounding the YAC128 mice in the early stage of our studies. We greatly appreciate the efforts of Dr Michael Rowe and Charlotte Wiest in initiating and expanding the colonies of the two mouse models of HD in our laboratory. We also thank Emily Fessler and Ioline Henter of the NIMH, NIH, for critical review and editorial assistance with this paper. This work was supported by the Intramural Research Program of the National Institute of Mental Health, National Institutes of Health, Department of Health and Human Services (IRP-NIMH-NIH-DHHS), and by the HSU family gift fund.

\section{DISCLOSURE}

The authors declare no conflict of interest.

\section{REFERENCES}

Beaulieu JM, Zhang X, Rodriguiz RM, Sotnikova TD, Cools MJ, Wetsel WC et al (2008). Role of GSK3 beta in behavioral abnormalities induced by serotonin deficiency. Proc Natl Acad Sci USA 105: 1333-1338.

Bemelmans AP, Horellou P, Pradier L, Brunet I, Colin P, Mallet J (1999). Brain-derived neurotrophic factor-mediated protection of striatal neurons in an excitotoxic rat model of Huntington's disease, as demonstrated by adenoviral gene transfer. Hum Gene Ther 10: 2987-2997.

Bersudsky Y, Shaldubina A, Belmaker RH (2007). Lithium's effect in forced-swim test is blood level dependent but not dependent on weight loss. Behav Pharmacol 18: 77-80.

Beurel E, Michalek SM, Jope RS (2010). Innate and adaptive immune responses regulated by glycogen synthase kinase-3 (GSK3). Trends Immunol 31: 24-31.

Buitrago MM, Schulz JB, Dichgans J, Luft AR (2004). Short and long-term motor skill learning in an accelerated rotarod training paradigm. Neurobiol Learn Mem 81: 211-216.

Canals JM, Pineda JR, Torres-Peraza JF, Bosch M, Martin-Ibanez $\mathrm{R}$, Munoz MT et al (2004). Brain-derived neurotrophic factor regulates the onset and severity of motor dysfunction associated with enkephalinergic neuronal degeneration in Huntington's disease. J Neurosci 24: 7727-7739.

Carmichael J, Sugars KL, Bao YP, Rubinsztein DC (2002). Glycogen synthase kinase-3beta inhibitors prevent cellular polyglutamine toxicity caused by the Huntington's disease mutation. J Biol Chem 277: 33791-33798.
Carter RJ, Lione LA, Humby T, Mangiarini L, Mahal A, Bates GP et al (1999). Characterization of progressive motor deficits in mice transgenic for the human Huntington's disease mutation. J Neurosci 19: 3248-3257.

Chalecka-Franaszek E, Chuang DM (1999). Lithium activates the serine/threonine kinase Akt-1 and suppresses glutamate-induced inhibition of Akt-1 activity in neurons. Proc Natl Acad Sci USA 96: 8745-8750.

Chan HY, Warrick JM, Gray-Board GL, Paulson HL, Bonini NM (2000). Mechanisms of chaperone suppression of polyglutamine disease: selectivity, synergy and modulation of protein solubility in Drosophila. Hum Mol Genet 9: 2811-2820.

Chen G, Huang LD, Jiang YM, Manji HK (1999). The moodstabilizing agent valproate inhibits the activity of glycogen synthase kinase-3. J Neurochem 72: 1327-1330.

Chiang MC, Chen HM, Lee YH, Chang HH, Wu YC, Soong BW et al (2007). Dysregulation of C/EBPalpha by mutant Huntingtin causes the urea cycle deficiency in Huntington's disease. Hum Mol Genet 16: 483-498.

Chiu CT, Chuang DM (2010). Molecular actions and therapeutic potential of lithium in preclinical and clinical studies of CNS disorders. Pharmacol Ther 128: 281-304.

Chuang DM (2005). The antiapoptotic actions of mood stabilizers: molecular mechanisms and therapeutic potentials. Ann NY Acad Sci 1053: 195-204.

Chuang DM, Leng Y, Marinova Z, Kim HJ, Chiu CT (2009). Multiple roles of HDAC inhibition in neurodegenerative conditions. Trends Neurosci 32: 591-601.

Crawley JN (1985). Exploratory behavior models of anxiety in mice. Neurosci Biobehav Rev 9: 37-44.

Cryan JF, Mombereau C (2004). In search of a depressed mouse: utility of models for studying depression-related behavior in genetically modified mice. Mol Psychiatry 9: 326-357.

Cryan JF, Mombereau C, Vassout A (2005). The tail suspension test as a model for assessing antidepressant activity: review of pharmacological and genetic studies in mice. Neurosci Biobehav Rev 29: 571-625.

de Angelis L (1992). The anxiogenic-like effects of pentylenetetrazole in mice treated chronically with carbamazepine or valproate. Methods Find Exp Clin Pharmacol 14: 767-771.

De Sarno P, Li X, Jope RS (2002). Regulation of Akt and glycogen synthase kinase-3 beta phosphorylation by sodium valproate and lithium. Neuropharmacology 43: 1158-1164.

Di ML, Squitieri F, Napolitano G, Campanella G, Trofatter JA, Conneally PM (1993). Suicide risk in Huntington's disease. J Med Genet 30: 293-295.

Duan W, Guo Z, Jiang H, Ware M, Li XJ, Mattson MP (2003). Dietary restriction normalizes glucose metabolism and BDNF levels, slows disease progression, and increases survival in huntingtin mutant mice. Proc Natl Acad Sci USA 100: 2911-2916.

Duan W, Peng Q, Masuda N, Ford E, Tryggestad E, Ladenheim B et al (2008). Sertraline slows disease progression and increases neurogenesis in N171-82Q mouse model of Huntington's disease. Neurobiol Dis 30: 312-322.

Feng HL, Leng Y, Ma CH, Zhang J, Ren M, Chuang DM (2008). Combined lithium and valproate treatment delays disease onset, reduces neurological deficits and prolongs survival in an amyotrophic lateral sclerosis mouse model. Neuroscience 155: 567-572.

Ferrer I, Goutan E, Marin C, Rey MJ, Ribalta T (2000). Brainderived neurotrophic factor in Huntington disease. Brain Res 866: 257-261.

File SE, Mahal A, Mangiarini L, Bates GP (1998). Striking changes in anxiety in Huntington's disease transgenic mice. Brain Res 805: 234-240.

Fink AL (1999). Chaperone-mediated protein folding. Physiol Rev 79: 425-449.

Friedlander RM (2003). Apoptosis and caspases in neurodegenerative diseases. $N$ Engl J Med 348: 1365-1375. 
Fujimoto M, Takaki E, Hayashi T, Kitaura Y, Tanaka Y, Inouye S et al (2005). Active HSF1 significantly suppresses polyglutamine aggregate formation in cellular and mouse models. J Biol Chem 280: 34908-34916.

Fukumoto T, Morinobu S, Okamoto Y, Kagaya A, Yamawaki S (2001). Chronic lithium treatment increases the expression of brain-derived neurotrophic factor in the rat brain. Psychopharmacology (Berl) 158: 100-106.

Göttlicher M, Minucci S, Zhu P, Kramer OH, Schimpf A, Giavara S et al (2001). Valproic acid defines a novel class of HDAC inhibitors inducing differentiation of transformed cells. EMBO J 20: 6969-6978.

Gould TD, Chen G, Manji HK (2004). In vivo evidence in the brain for lithium inhibition of glycogen synthase kinase-3. Neuropsychopharmacology 29: 32-38.

Gould TD, O’Donnell KC, Dow ER, Du J, Chen G, Manji HK (2008). Involvement of AMPA receptors in the antidepressant-like effects of lithium in the mouse tail suspension test and forced swim test. Neuropharmacology 54: 577-587.

Grimes CA, Jope RS (2001). The multifaceted roles of glycogen synthase kinase 3beta in cellular signaling. Prog Neurobiol 65: 391-426.

Gusella JF, MacDonald ME (1995). Huntington's disease. Semin Cell Biol 6: 21-28.

Hamilton JM, Salmon DP, Corey-Bloom J, Gamst A, Paulsen JS, Jerkins S et al (2003). Behavioural abnormalities contribute to functional decline in Huntington's disease. J Neurol Neurosurg Psychiatry 74: 120-122.

Hartl FU, Hayer-Hartl M (2002). Molecular chaperones in the cytosol: from nascent chain to folded protein. Science 295: 1852-1858.

Hashimoto R, Takei N, Shimazu K, Christ L, Lu B, Chuang DM (2002). Lithium induces brain-derived neurotrophic factor and activates TrkB in rodent cortical neurons: an essential step for neuroprotection against glutamate excitotoxicity. Neuropharmacology 43: 1173-1179.

Hay DG, Sathasivam K, Tobaben S, Stahl B, Marber M, Mestril R et al (2004). Progressive decrease in chaperone protein levels in a mouse model of Huntington's disease and induction of stress proteins as a therapeutic approach. Hum Mol Genet 13: 1389-1405.

Hickey MA, Chesselet MF (2003). Apoptosis in Huntington's disease. Prog Neuropsychopharmacol Biol Psychiatry 27: 255-265.

Hickey MA, Kosmalska A, Enayati J, Cohen R, Zeitlin S, Levine MS et al (2008). Extensive early motor and non-motor behavioral deficits are followed by striatal neuronal loss in knock-in Huntington's disease mice. Neuroscience 157: 280-295.

Hodges A, Strand AD, Aragaki AK, Kuhn A, Sengstag T, Hughes G et al (2006). Regional and cellular gene expression changes in human Huntington's disease brain. Hum Mol Genet 15: 965-977.

Huang HC, Klein PS (2006). Multiple roles for glycogen synthase kinase-3 as a drug target in Alzheimer's disease. Curr Drug Targets 7: 1389-1397.

Jana NR, Tanaka M, Wang G, Nukina N (2000). Polyglutamine lengthdependent interaction of Hsp40 and Hsp70 family chaperones with truncated N-terminal huntingtin: their role in suppression of aggregation and cellular toxicity. Hum Mol Genet 9: 2009-2018.

Jones BJ, Roberts DJ (1968). A rotarod suitable for quantitative measurements of motor incoordination in naive mice. Naunyn Schmiedebergs Arch Exp Pathol Pharmakol 259: 211.

Jope RS, Yuskaitis CJ, Beurel E (2007). Glycogen synthase kinase-3 (GSK3): inflammation, diseases, and therapeutics. Neurochem Res 32: 577-595.

Kaidanovich-Beilin O, Milman A, Weizman A, Pick CG, EldarFinkelman H (2004). Rapid antidepressive-like activity of specific glycogen synthase kinase-3 inhibitor and its effect on beta-catenin in mouse hippocampus. Biol Psychiatry 55: 781-784.

Kells AP, Fong DM, Dragunow M, During MJ, Young D, Connor B (2004). AAV-mediated gene delivery of BDNF or GDNF is neuroprotective in a model of Huntington disease. Mol Ther 9: 682-688.

Kim HJ, Rowe M, Ren M, Hong JS, Chen PS, Chuang DM (2007). Histone deacetylase inhibitors exhibit anti-inflammatory and neuroprotective effects in a rat permanent ischemic model of stroke: multiple mechanisms of action. J Pharmacol Exp Ther 321: 892-901.

Klein PS, Melton DA (1996). A molecular mechanism for the effect of lithium on development. Proc Natl Acad Sci USA 93: 8455-8459.

Klivenyi P, Bende Z, Hartai Z, Penke Z, Nemeth H, Toldi J et al (2006). Behaviour changes in a transgenic model of Huntington's disease. Behav Brain Res 169: 137-141.

Leng Y, Liang $\mathrm{MH}$, Ren M, Marinova Z, Leeds P, Chuang DM (2008). Synergistic neuroprotective effects of lithium and valproic acid or other histone deacetylase inhibitors in neurons: roles of glycogen synthase kinase-3 inhibition. J Neurosci 28: 2576-2588.

Liaw YW, Liu YW, Chen BK, Chang WC (1998). Induction of 12-lipoxygenase expression by phorbol 12-myristate 13-acetate in human epidermoid carcinoma A431 cells. Biochim Biophys Acta 1389: 23-33.

MacDonald ME, Ambrose CM, Duyao MP, Myers RH, Lin C, Srinidhi L et al (1993). A novel gene containing a trinucleotide repeat that is expanded and unstable on Huntington's disease chromosomes. Cell 72: 971-983.

Marinova Z, Ren M, Wendland JR, Leng Y, Liang MH, Yasuda S et al (2009). Valproic acid induces functional heat-shock protein 70 via class I histone deacetylase inhibition in cortical neurons: a potential role of Sp1 acetylation. J Neurochem 111: 976-987.

Martin JB, Gusella JF (1986). Huntington's disease. Pathogenesis and management. $N$ Engl J Med 315: 1267-1276.

Menalled L, El-Khodor BF, Patry M, Suarez-Farinas M, Orenstein SJ, Zahasky B et al (2009). Systematic behavioral evaluation of Huntington's disease transgenic and knock-in mouse models. Neurobiol Dis 35: 319-336.

Morales LM, Estevez J, Suarez H, Villalobos R, Chacin de BL, Bonilla E (1989). Nutritional evaluation of Huntington disease patients. Am J Clin Nutr 50: 145-150.

Nakao N, Brundin P, Funa K, Lindvall O, Odin P (1995). Trophic and protective actions of brain-derived neurotrophic factor on striatal DARPP-32-containing neurons in vitro. Brain Res Dev Brain Res 90: 92-101.

O'Brien WT, Harper AD, Jove F, Woodgett JR, Maretto S, Piccolo S et al (2004). Glycogen synthase kinase-3beta haploinsufficiency mimics the behavioral and molecular effects of lithium. J Neurosci 24: 6791-6798.

Omata N, Chiu CT, Moya PR, Leng Y, Wang Z, Hunsberger JG et al (2011). Lentivirally mediated GSK-3beta silencing in the hippocampal dentate gyrus induces antidepressant-like effects in stressed mice. Int J Neuropsychopharmacol 14: 711-717.

Phiel CJ, Zhang F, Huang EY, Guenther MG, Lazar MA, Klein PS (2001). Histone deacetylase is a direct target of valproic acid, a potent anticonvulsant, mood stabilizer, and teratogen. $J$ Biol Chem 276: 36734-36741.

Porsolt RD, Bertin A, Jalfre M (1977). Behavioral despair in mice: a primary screening test for antidepressants. Arch Int Pharmacodyn Ther 229: 327-336.

Pouladi MA, Graham RK, Karasinska JM, Xie Y, Santos RD, Petersen A et al (2009). Prevention of depressive behaviour in the YAC128 mouse model of Huntington disease by mutation at residue 586 of huntingtin. Brain 132: 919-932.

Ren M, Leng Y, Jeong M, Leeds PR, Chuang DM (2004). Valproic acid reduces brain damage induced by transient focal cerebral ischemia in rats: potential roles of histone deacetylase inhibition and heat shock protein induction. J Neurochem 89: 1358-1367.

Ren M, Senatorov VV, Chen RW, Chuang DM (2003). Postinsult treatment with lithium reduces brain damage and facilitates 
neurological recovery in a rat ischemia/reperfusion model. Proc Natl Acad Sci USA 100: 6210-6215.

Rosa AO, Kaster MP, Binfare RW, Morales S, Martin-Aparicio E, Navarro-Rico ML et al (2008). Antidepressant-like effect of the novel thiadiazolidinone NP031115 in mice. Prog Neuropsychopharmacol Biol Psychiatry 32: 1549-1556.

Rowe MK, Chuang DM (2004). Lithium neuroprotection: molecular mechanisms and clinical implications. Expert Rev Mol Med 6: 1-18.

Rowe MK, Wiest C, Chuang DM (2007). GSK-3 is a viable potential target for therapeutic intervention in bipolar disorder. Neurosci Biobehav Rev 31: 920-931.

Rubinsztein DC (2002). Lessons from animal models of Huntington's disease. Trends Genet 18: 202-209.

Ryves WJ, Harwood AJ (2001). Lithium inhibits glycogen synthase kinase- 3 by competition for magnesium. Biochem Biophys Res Commun 280: 720-725.

Sangdee C, Franz DN (1978). Lithium-induced enhancement of 5-HT transmission at a central synapse. Commun Psychopharmacol 2: 191-198.

Saudou F, Finkbeiner S, Devys D, Greenberg ME (1998). Huntingtin acts in the nucleus to induce apoptosis but death does not correlate with the formation of intranuclear inclusions. Cell 95: 55-66.

Schilling G, Becher MW, Sharp AH, Jinnah HA, Duan K, Kotzuk JA et al (1999). Intranuclear inclusions and neuritic aggregates in transgenic mice expressing a mutant $\mathrm{N}$-terminal fragment of huntingtin. Hum Mol Genet 8: 397-407.

Schroeder FA, Lin CL, Crusio WE, Akbarian S (2007). Antidepressant-like effects of the histone deacetylase inhibitor, sodium butyrate, in the mouse. Biol Psychiatry 62: 55-64.

Shepherd JK, Grewal SS, Fletcher A, Bill DJ, Dourish CT (1994). Behavioural and pharmacological characterisation of the elevated "zero-maze" as an animal model of anxiety. Psychopharmacology (Berl) 116: 56-64.

Slow EJ, van RJ, Rogers D, Coleman SH, Graham RK, Deng Y et al (2003). Selective striatal neuronal loss in a YAC128 mouse model of Huntington disease. Hum Mol Genet 12: 1555-1567.

Stack EC, Ferrante RJ (2007). Huntington's disease: progress and potential in the field. Expert Opin Investig Drugs 16: 1933-1953.

Steru L, Chermat R, Thierry B, Simon P (1985). The tail suspension test: a new method for screening antidepressants in mice. Psychopharmacology (Berl) 85: 367-370.

Sugars KL, Rubinsztein DC (2003). Transcriptional abnormalities in Huntington disease. Trends Genet 19: 233-238.

Tekin S, Cummings JL (2002). Frontal-subcortical neuronal circuits and clinical neuropsychiatry: an update. J Psychosom Res 53: 647-654.
Treiser SL, Cascio CS, O'Donohue TL, Thoa NB, Jacobowitz DM, Kellar KJ (1981). Lithium increases serotonin release and decreases serotonin receptors in the hippocampus. Science 213: 1529-1531.

Trejo A, Tarrats RM, Alonso ME, Boll MC, Ochoa A, Velasquez L (2004). Assessment of the nutrition status of patients with Huntington's disease. Nutrition 20: 192-196.

Van Raamsdonk JM, Metzler M, Slow E, Pearson J, Schwab C, Carroll J et al (2007). Phenotypic abnormalities in the YAC128 mouse model of Huntington disease are penetrant on multiple genetic backgrounds and modulated by strain. Neurobiol Dis 26: 189-200.

Ventimiglia R, Mather PE, Jones BE, Lindsay RM (1995). The neurotrophins BDNF, NT-3 and NT-4/5 promote survival and morphological and biochemical differentiation of striatal neurons in vitro. Eur J Neurosci 7: 213-222.

Vonsattel JP, DiFiglia M (1998). Huntington disease. J Neuropathol Exp Neurol 57: 369-384.

Wheelock VL, Tempkin T, Marder K, Nance M, Myers RH, Zhao H et al (2003). Predictors of nursing home placement in Huntington disease. Neurology 60: 998-1001.

Woo NH, Lu B (2006). Regulation of cortical interneurons by neurotrophins: from development to cognitive disorders. Neuroscientist 12: 43-56.

Wood NI, Morton AJ (2003). Chronic lithium chloride treatment has variable effects on motor behaviour and survival of mice transgenic for the Huntington's disease mutation. Brain Res Bull 61: 375-383.

Yamanaka T, Miyazaki H, Oyama F, Kurosawa M, Washizu C, Doi $\mathrm{H}$ et al (2008). Mutant Huntingtin reduces HSP70 expression through the sequestration of NF-Y transcription factor. EMBO J 27: 827-839.

Yasuda S, Liang MH, Marinova Z, Yahyavi A, Chuang DM (2009). The mood stabilizers lithium and valproate selectively activate the promoter IV of brain-derived neurotrophic factor in neurons. Mol Psychiatry 14: 51-59.

Zadori D, Geisz A, Vamos E, Vecsei L, Klivenyi P (2009). Valproate ameliorates the survival and the motor performance in a transgenic mouse model of Huntington's disease. Pharmacol Biochem Behav 94: 148-153.

Zhang F, Phiel CJ, Spece L, Gurvich N, Klein PS (2003). Inhibitory phosphorylation of glycogen synthase kinase-3 (GSK-3) in response to lithium. Evidence for autoregulation of GSK-3. J Biol Chem 278: 33067-33077.

Zuccato C, Ciammola A, Rigamonti D, Leavitt BR, Goffredo D, Conti L et al (2001). Loss of huntingtin-mediated BDNF gene transcription in Huntington's disease. Science 293: 493-498.

Supplementary Information accompanies the paper on the Neuropsychopharmacology website (http://www.nature.com/npp) 